\title{
Slit/Robo Signaling Mediates Spatial Positioning of Spiral Ganglion Neurons during Development of Cochlear Innervation
}

\author{
Sheng-zhi Wang, ${ }^{1,2,4}$ Leena A. Ibrahim, ${ }^{1,5 *}$ Young J. Kim, ${ }^{1,2,5 *}$ Daniel A. Gibson, ${ }^{1,5 *}$ Haiwen C. Leung, ${ }^{1,3}$ Wei Yuan, ${ }^{1,2,6}$ \\ Ke K. Zhang, ${ }^{7}$ Huizhong W. Tao, ${ }^{1,3}$ Le Ma, ${ }^{1,3}$ and Li I. Zhang ${ }^{1,2}$ \\ 1Zilkha Neurogenetic Institute, ${ }^{2}$ Department of Physiology and Biophysics, ${ }^{3}$ Department of Cell and Neurobiology, ${ }^{4}$ Graduate Program in Physiology and \\ Biophysics, ${ }^{5}$ Neuroscience Graduate Program, Keck School of Medicine, University of Southern California, Los Angeles, California 90089, ${ }^{6}$ Department of \\ Otolaryngology of Southwest Hospital, Third Military Medical University, Chongqing, China 400038, and ${ }^{7}$ Department of Pathology, University of North \\ Dakota, Grand Forks, North Dakota 58202
}

During the development of periphery auditory circuits, spiral ganglion neurons (SGNs) extend their neurites to innervate cochlear hair cells (HCs) with their soma aggregated into a cluster spatially segregated from the cochlear sensory epithelium. The molecular mechanisms underlying this spatial patterning remain unclear. In this study, in situ hybridization in the mouse cochlea suggests that Slit2 and its receptor, Robo1/2, exhibit apparently complementary expression patterns in the spiral ganglion and its nearby region, the spiral limbus. In Slit2 and Robo1/2 mutants, the spatial restriction of SGNs was disrupted. Mispositioned SGNs were found to scatter in the space between the cochlear epithelium and the main body of spiral ganglion, and the neurites of mispositioned SGNs were misrouted and failed to innervate HCs. Furthermore, in Robo 1/2 mutants, SGNs were displaced toward the cochlear epithelium as an entirety. Examination of different embryonic stages in the mutants revealed that the mispositioning of SGNs was due to a progressive displacement to ectopic locations after their initial normal settlement at an earlier stage. Our results suggest that Slit/Robo signaling imposes a restriction force on SGNs to ensure their precise positioning for correct SGN-HC innervations.

\section{Introduction}

Neural circuit assembly relies on the proper control of spatial patterning of different cell populations during development. The molecular mechanisms underlying the patterning of neuronal cell bodies into distinct clusters remain not well understood, although previous studies have shown that cell migration mediated by extracellular cues, such as Reelin, provides an important mechanism to establish cortical layers (Marín and Rubenstein, 2003; Frotscher, 2010). The cochlea of the inner ear provides a good model to study the molecular regulation of spatial patterning of different cell groups during circuit assembly. In this peripheral auditory organ, sound signals converted by hair cells (HCs) are conveyed by spiral ganglion neurons (SGNs) to cochlear nucleus neurons in the brainstem. SGNs are the bipolar afferent neurons in the medial surface of the cochlear duct that

\footnotetext{
Received Dec. 14, 2012; revised June 8, 2013; accepted June 15, 2013

Author contributions: H.W.T., L.M. and L.I.Z. designed research; S.-z.W., L.A.I., Y.J.K., D.A.G., H.C.L., W.Y., and L.I.Z. performed research; S.-Z.W., K.K.Z., H.W.T., L.M., and L.I.Z. analyzed data; S.-z.W., H.W.T., and L.I.Z. wrote the paper.

This work was supported by grants to L.I.Z. from the National Institutes of Health (NIH, DCO08983) and the David and Lucile Packard Foundation, and to L.M. from the NIH (NS062047). H.W.T. was supported by an NIH Grant (EY019049). K.K.Z. was supported by NIH Grants P20RR016471 and P20GM103442. W.Y. was supported by National Science Foundation grants from China (30973301 and 81271080). We thank Dr. Xiwei Wu for the help on microarray experiments.

*L.A.I., Y.J.K., and D.A.G. contributed equally to this work.

Correspondence should be addressed to L.I.Zhang at the above address. E-mail: liizhang@usc.edu; or to L. Ma at the above address.E-mail: le.ma@usc.edu.

DOI:10.1523/JNEUROSCI.5736-12.2013

Copyright $\odot 2013$ the authors $\quad 0270-6474 / 13 / 3312242-13 \$ 15.00 / 0$
}

run in parallel with HCs in the cochlear sensory epithelium. They form stereotyped connectivity with HCs in adult cochleae. During development, SGNs migrate out from the otocyst and cluster in the Rosenthal's canal to form an aggregation spatially separated from the cochlear epithelial layer (Fig. 1; Ruben, 1967). SGNs subsequently extend their peripheral neurites into the cochlear sensory epithelium to innervate HCs, forming a topographic innervation pattern as revealed by organized radial fibers (RFs; Fig. 2A-D; Appler and Goodrich, 2011; Nayagam et al., 2011; Yang et al., 2011). Although previous studies have characterized in detail the differentiation and morphological development of HCs and SGNs (Kelley, 2006; Grimsley-Myers et al., 2009; Kelly and Chen, 2009; Lu et al., 2011; Coate et al., 2012; Groves and Fekete, 2012), the molecular mechanisms underlying the spatial patterning of SGNs during their innervation of HCs are largely elusive.

In this study, we demonstrate the role of an axon guidance cue, Slit2 in controlling the spatial positioning of SGN cell bodies in the cochlear development. Based on microarray analysis and in situ hybridization, we found that Slit2 was strongly expressed in the spiral limbus (SL) with the Slit2 receptors Robol and Robo2, expressed in spiral ganglion (SG), forming an apparently local complementary expression pattern. In mouse mutants for Slit2 and for both Robol and Robo2 (referred as Robo1/2 in the text), the spatial restriction of SGNs was disrupted with more severe phenotypes in the Robo1/2 mutant. By tracing developmental changes, we found that the displacement of SGNs occurred progressively after their initial normal settlement at an earlier stage. 


\section{TOP VIEW}

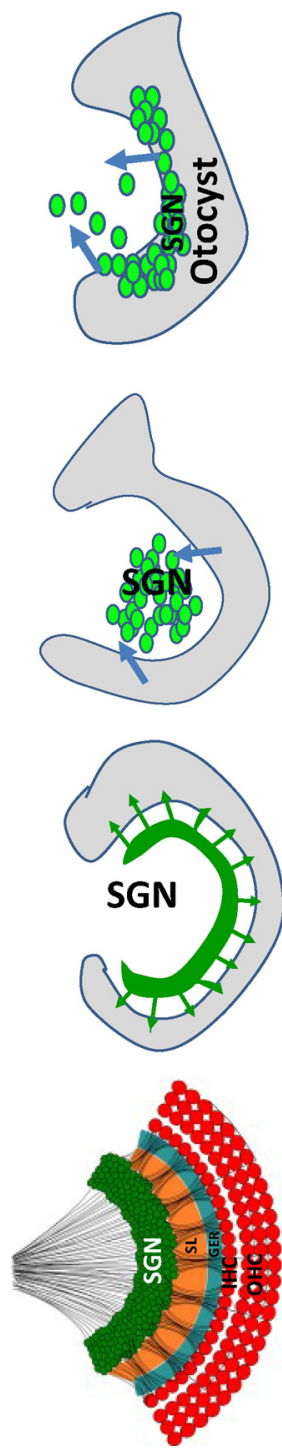

SIDE VIEW
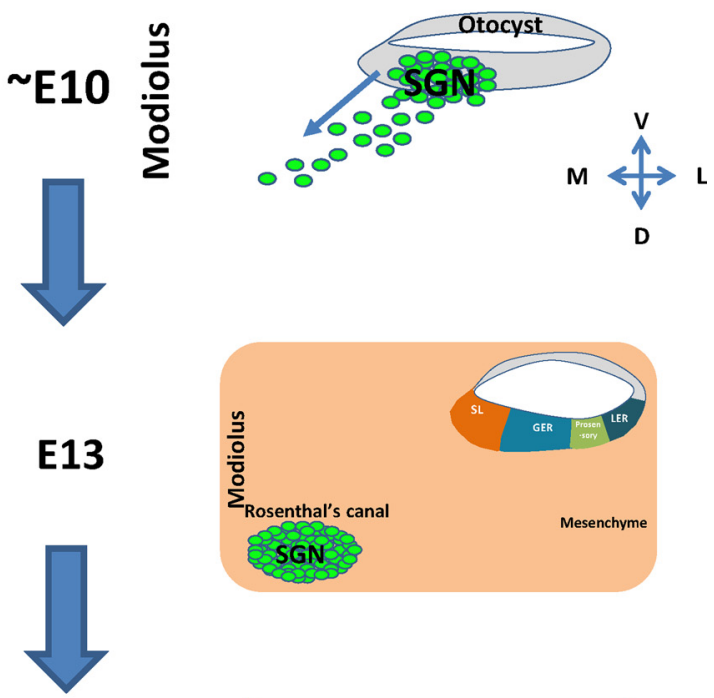

E14
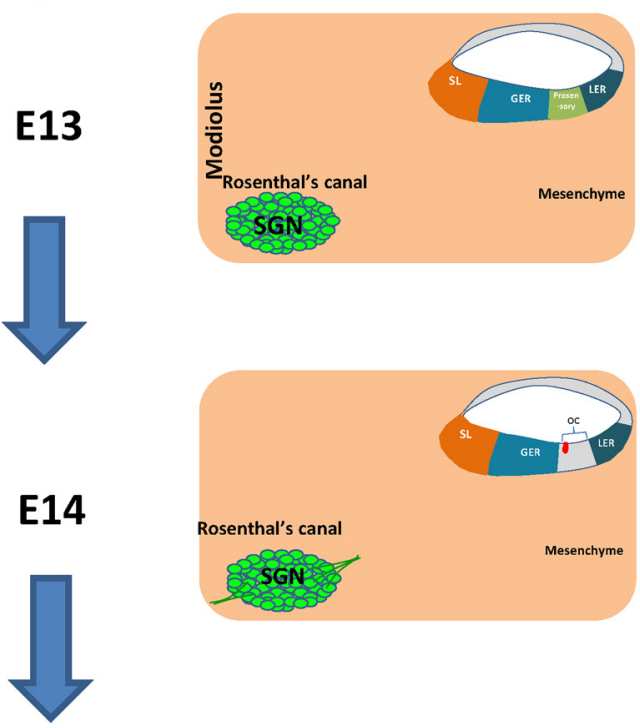

E16

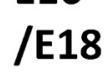

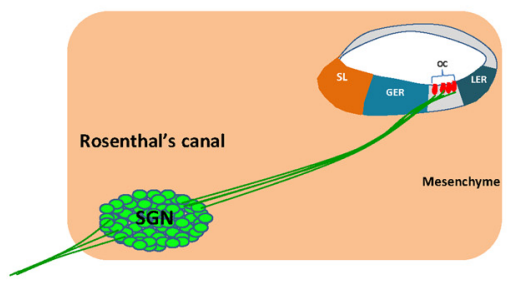

Figure 1. Schematic illustration of the assembly of peripheral auditory circuitry. Early in development ( E10), SGNs delaminate from the developing otocyst and coalesce to form a tight cluster in the Rosenthal's canal close to the modiolus by E13. SGNs subsequently extend their peripheral neurites (starting from E14) to innervate $\mathrm{HCs}$ located in the organ of $\mathrm{Corti}(\mathrm{OC}$ ) at the cochlear epithelium while their somas are restricted within the Rosenthal's canal, forming topographically organized connectivity.

Thus, Slit/Robo signaling serves to prevent SGNs from escaping from the Rosenthal's canal and invading the tissue around the cochlear sensory epithelium. Our results revealed a previously unrecognized role of Slit/Robo signaling in maintaining the spatial restriction of distinct cell assemblies. Such restricted spatial patterning may be an important basis for the formation of precise innervation patterns in the peripheral nervous system.

\section{Materials and Methods}

Mouse strains. Mice were handled according to the protocols approved by the Institutional Animal Care and Use Committees at the University of Southern California. Mice of either sex were used and generated in a mixed CD-1/129Sv/C57BL/6 background. To generate Slit mutants, we crossed Slit $1^{-/-} ;$Slit $^{+/-}$, Slit2 $2^{+/-}$, Slit $3^{+/-}$animals and obtained the desired mutants. Robo mutants were obtained by crossing double heterozygous Robo1;Robo2 animals, which have the two mutant alleles (1.8 megabases apart) already linked to the same chromosome 16 (Ma and Tessier-Lavigne, 2007). Genotyping of Slit1, Slit2, Slit3, Robo1, and
Robo2 was done by PCR as described previously (Plump et al., 2002; Yuan et al., 2003; Grieshammer et al., 2004; Sabatier et al., 2004). Genotyping of Neurogenin1-cre/ERT2 and Ail4 (ROSA-LSL-tdTomato) was done by PCR following previous descriptions (Koundakjian et al., 2007; Madisen et al., 2010). All the mouse mutants examined in the current study are lethal at birth, which limited our examination of cochlear innervation pattern at embryonic stages only. Plug dates were designated as embryonic day 0 (E0).

Tissue dissection, FM1-43 staining, and FACS. Cochlear epithelium was dissected from mouse pups between postnatal day (P) 5 to $\mathrm{P} 7$ as previously described (Doetzlhofer et al., 2006; Lelli et al., 2009). For FM1-43 dye staining, whole-mount cochleae from wild-type mice were bathed with $5 \mu \mathrm{M}$ FM1-43 (Invitrogen) for $30 \mathrm{~s}$ followed by extensive wash with PBS. SG was trimmed away from both the FM1-43-stained wild-type cochlea and Parvalbumin (PV)-Cre; Ai14 (ROSA-LSLtdTomato) cochlea. Tissues from both sources were then treated with activated papain (20 $\mathrm{U} / \mathrm{ml}$ plus $1 \mathrm{~mm}$ L-cysteine; Worthington) for $20 \mathrm{~min}$ followed by 2 min crude trypsin $(0.5$ $\mathrm{mg} / \mathrm{ml}$; Sigma-Aldrich) treatment. DMEM (Invitrogen) plus 10\% FBS were added and tissue was triturated to achieve complete dissociation. FACS was performed at Flow Cytometry Core Facility at the University of Southern California. Cell suspensions were fed into a BDAriaII sorter and purified using $488 \mathrm{~nm}$ laser excitation and $100 \mu \mathrm{m}$ CytoNozzle. Distinct cell populations were collected into DMEM plus 10\% FBS and pelleted down through centrifuge.

RNA amplification and microarray data analysis. Cells from different experiments were pooled. RNA was extracted using PicoPure RNA isolation kit (Arcturus) from distinct purified cell populations. Three independent pools of RNA from each population were amplified using WT-Ovation Pico amplification kit $(\mathrm{Nu}-$ gen) and labeled for microarray experiments performed at the Children's Hospital Los Angeles Genomics Core. Samples were profiled on GeneChip Mouse Genome 430 2.0 Array (Affymetrix). Microarray data analysis was conducted within $\mathrm{R}$ environment. The raw expression data were normalized with MAS5.0 algorithm and filtered before logarithm transformation (Bolstad et al., 2003). Pairwise comparison for each probe set between the two groups was performed by empirical Bayes method, and differentially expressed probe sets were identified as having an absolute signal $\log$ ratio $\geq 1.0$, and a false discovery rate value $\leq 5 \%$ (Smyth, 2004). Gene annotation and ontology information was obtained from the National Center for Biotechnology Information, NetAffx, the Gene Ontology Consortium, and the Kyoto Encyclopedia of Genes and Genomes. Significant enrichment of specific gene sets was assessed with gene set analysis method (Efron and Tibshirani, 2007). Gene set information was obtained from Gene Set Enrichment Analysis website (Subramanian et al., 2005).

Immunohistochemistry and in situ hybridization. Whole-mount cochleae were dissected from embryos at specific stages using timely pregnant females and fixed with $4 \%$ PFA overnight. The cochlea was first permeabilized with $0.5 \%$ Triton X-100 for $10 \mathrm{~min}$, blocked with $10 \%$ serum plus 3\% BSA in PBS for $2 \mathrm{~h}$ at room temperature, and then incubated with first antibody overnight at $4^{\circ} \mathrm{C}$. After washout, Alexa- 
A

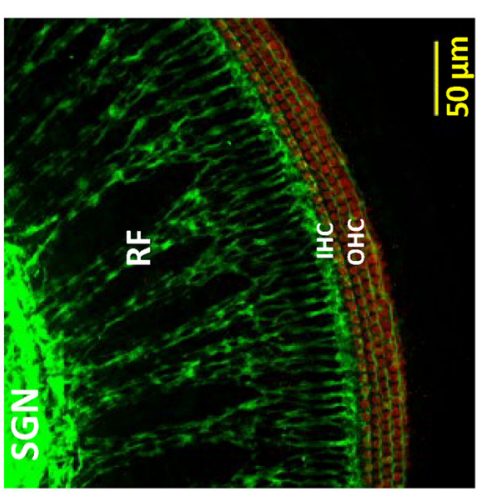

C

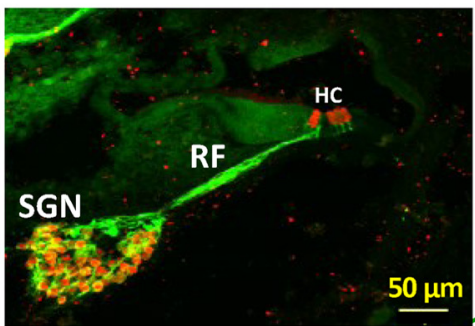

G

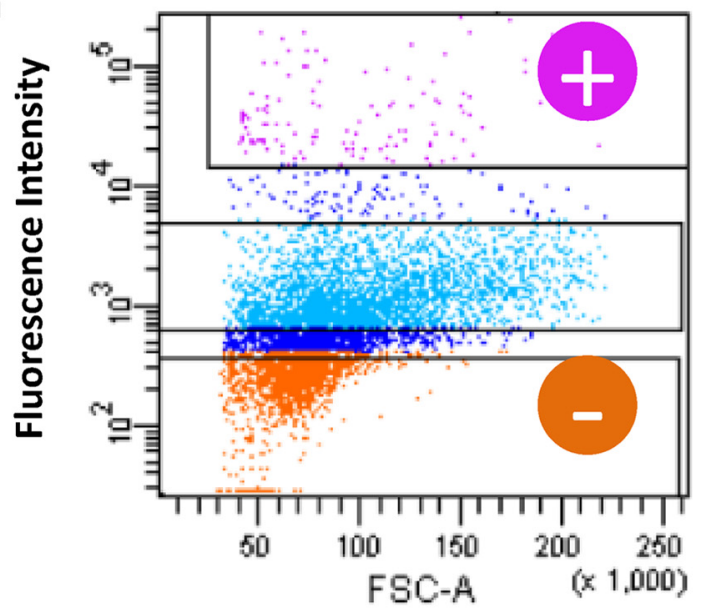

B
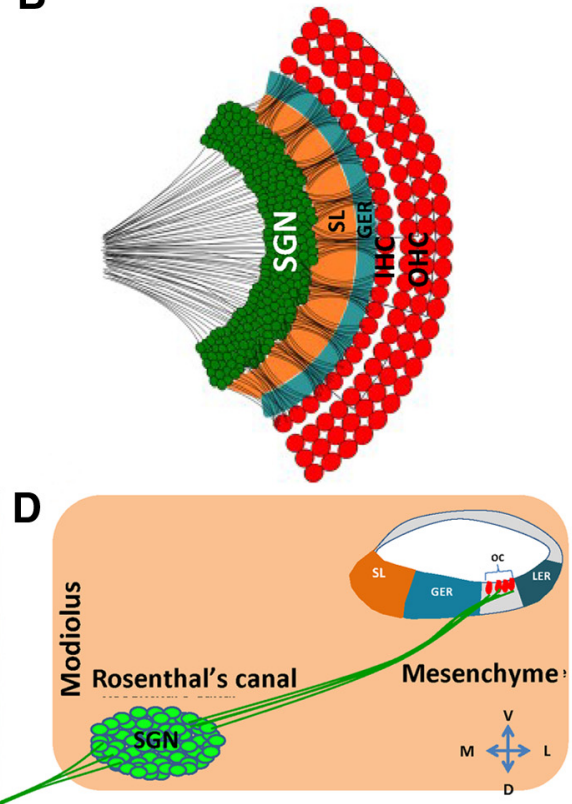

E

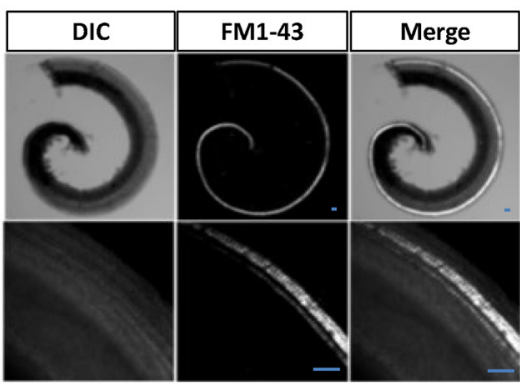

F

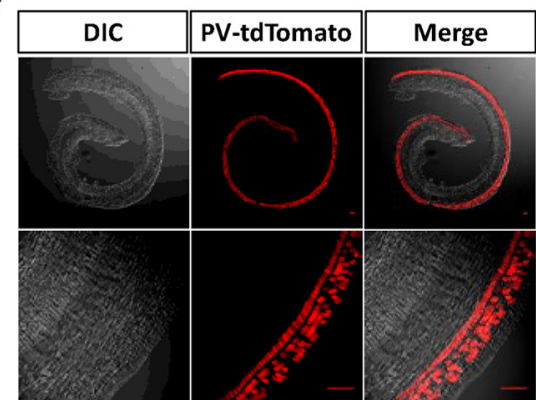

H
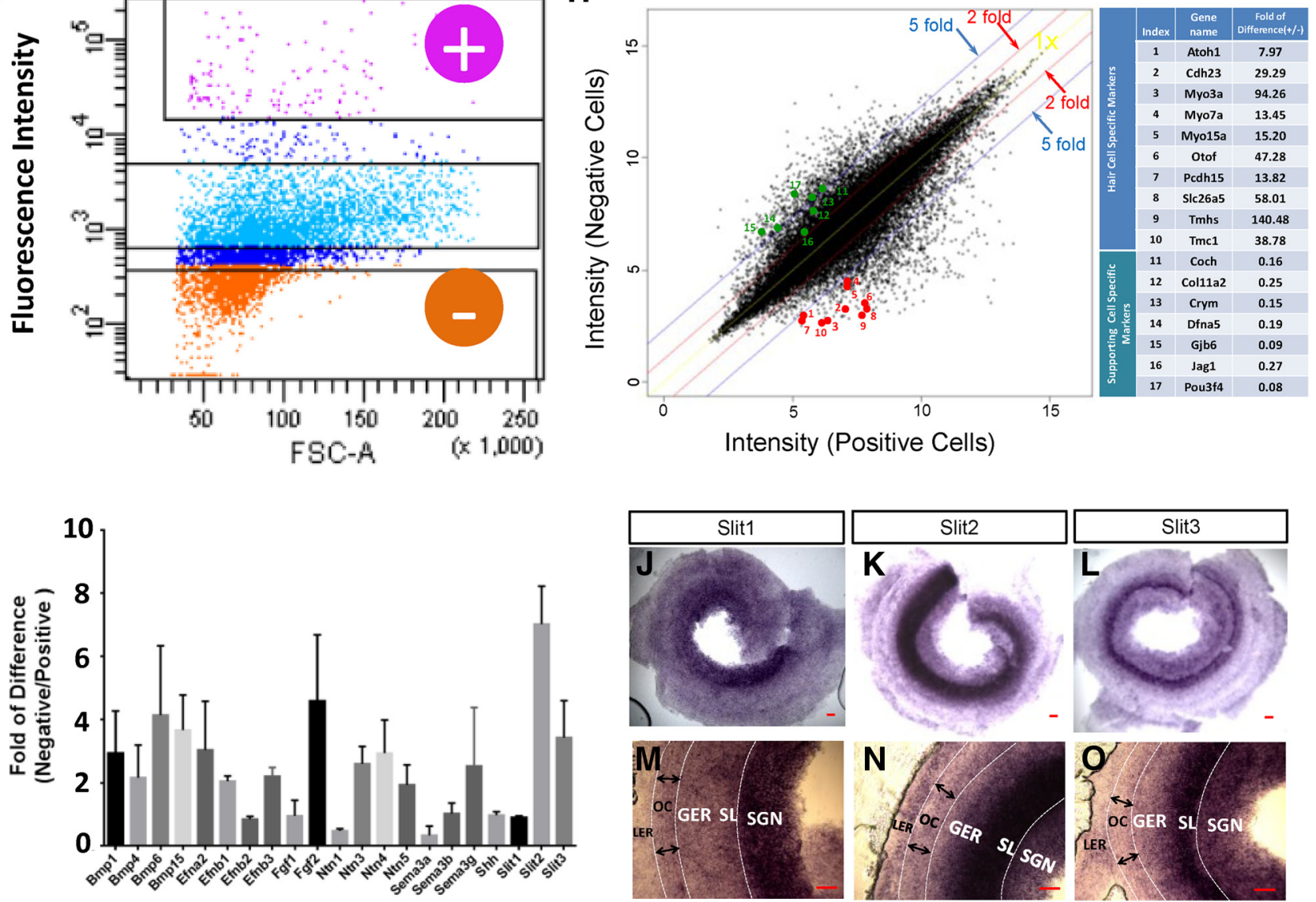

Figure 2. Gene expression analysis to identify Slit molecules as candidates to regulate the spatial patterning of SGNs. $\boldsymbol{A}-\boldsymbol{D}$, The SGN-HC innervation pattern at P1. $\boldsymbol{A}, \boldsymbol{B}$, Top view. $\boldsymbol{C}, \boldsymbol{D}$, Cross-section view. Green, TUJ1 staining; red, Myo6 staining in $A$ and PV staining in $C$. $B$ and $D$ indicate that SGN somas are restricted in the Rosenthal's canal while their peripheral axons penetrate through the otic mesenchyme and GER to innervate HCs (red) in the organ of Corti (OC). LER, Lesser epithelial ridge (or outer sulcus). $E$, Differential interference contrast (DIC) and fluorescence images of a wild-type cochlea at P6 stained with the styryl dye FM1-43. Top, Whole cochlea. Bottom, Higher-magnification images. Scale bar: $50 \mu \mathrm{m}$. F, Images of a cochlea of a PV-Cre; Ai14 mouse at P6. Scale bar, $50 \mu \mathrm{m}$. G, Gating configuration of FACS for separating HCs (fluorescence-positive population as marked by " +") from other cochlear cells (negative population as marked by " - ") based on fluorescence intensity. $\boldsymbol{H}$, Plot of the expression value of individual probes in the negative cell population versus positive cell population. Fold difference of $1 \times, 2 \times$, and $5 \times$ is marked by the yellow, red, and blue line respectively. Selected HC-specific genes (1-10 in the table) and supporting cell-specific genes (11-17 in the table) are highlighted by the red and green circles respectively. I, Fold of difference between the negative and positive cell populations for selected axon guidance molecules and morphogens in the microarray analysis. $N=3 . B a r=S D$. $J-0, I n$ situ hybridization of Slit7 $(\boldsymbol{J}, \boldsymbol{M})$, Slitz $(\boldsymbol{K}, \boldsymbol{N})$, and Slit3 $(\boldsymbol{L}, \mathbf{0})$ molecules in the whole-mount cochlea at E16. $\boldsymbol{M}-\mathbf{0}$ are higher-magnification images of $\boldsymbol{J}-\boldsymbol{L}$ respectively. Scale bar, $50 \mu \mathrm{m}$. 
conjugated secondary antibodies (1:800; Invitrogen) were added for $2 \mathrm{~h}$ at room temperature. Confocal $z$-stack images were obtained using Fluoview1000 (Olympus), projected using National Institutes of Health ImageJ, and then further processed using Inkscape. Antibodies used in this study and their dilution were as follows: Alexa488-conjugated TUJ1 mouse antibody (1:300; Covance), PV (rabbit polyclonal antibody; 1:600; Swant), MyoVI (rabbit polyclonal antibody; 1:600; Millipore), Alexa546-conjugated goat anti-rabbit IgG antibodies (1:800; Invitrogen). In situ hybridization was performed on whole-mount cochleae using digoxigenin-labeled cRNA probes following previous descriptions (Zine et al., 2001). Probes were generated using the templates previously published: Slit1, Slit2, Slit3, Robo1, Robo2, and Rig1 (Brose et al., 1999).

Image analysis. All the confocal image stacks were processed in Fiji (ImageJ) software and 3D reconstructions were performed using Neurolucida software. The positions of inner HCs and the boundaries of SG were identified based on the immunostaining signals of MYO6 and TUJ1, respectively, from the image series of the confocal $Z$ stack and marked by red and blue dotted lines, respectively, on the $Z$ projection images (see Figs. 6, 7). For early stages [embryonic day (E) 14], when HCs have not been marked by Myo6 immunostaining, we outlined the boundary of the cochlear lateral wall with white dotted lines instead. We measured the radial distance from the lateral boundary of SG to inner HCs (SGN-IHC distance) or the cochlear lateral wall (SGN-LW distance) for every fourth RF bundles along the base-apex axis. These measurements were plotted against their corresponding positions along the base-apex axis of the cochlea for selected examples from different genotypes. For consistency, statistical comparisons between different genotypes were focused on the middle part of the cochlea along the base-apex axis. To quantify the expansion of SGs in Robo mutants, we measured the width of SGs similarly as we did for SGN-IHC distance for each mutant tissue as well as wild-type tissues and then we subtracted the averaged width of wild-type tissues from each mutant tissue and plotted the values against different developmental stages.

\section{Results \\ Identifying Slit as a potential candidate for shaping cochlear patterning}

To identify genes that are important for the patterning of SGN-HC innervations, we screened for genes that are differentially expressed in nonsensory cells of the cochlear epithelium and HCs by performing a microarray transcriptome analysis. In particular, we focused on genes that are enriched in nonsensory cells, as it has been observed previously that in mouse mutants lacking HCs or mutants with immature HCs, SGNs are correctly positioned and are able to innervate the sensory epithelium (Xiang et al., 1998, 2003; Fritzsch et al., 2005).

We took two complementary approaches to specifically label HCs so that we could separate them from nonsensory cells during P5-P7. In the first approach, we used the styryl dye FM1-43, which can permeate the mechanotransduction channel of HCs and has been used to study the acquisition of mechanosensitivity in HCs (Gale et al., 2001; Géléoc and Holt, 2003; Meyers et al., 2003; Lelli et al., 2009). Consistent with previous reports, FM1-43 was able to label HCs robustly, whereas other cells in the cochlea epithelium were not labeled (Fig. 2E; Materials and Methods). In the second approach, we screened several Cre-driver mouse lines with the Cre expression controlled by the promoters of various calcium-binding proteins. We found that in the PV-Cre line (Hippenmeyer et al., 2005), Cre activity in the cochlea was limited to HCs, although the outer HCs were labeled in a mosaic pattern, as shown by the red fluorescence pattern in the PV-Cre mice crossed with a Cre-dependent tdTomato reporter line, Ai14 (Madisen et al., 2010; Fig. 2F). In addition to HCs, SGNs could be significantly labeled by both approaches (data not shown) and were trimmed away during the tissue dissection step.

Combining the two approaches, we purified HCs and nonsensory cells of the cochlea by FACS (Fig. 2G; Materials and Meth- ods). After sorting, we observed $>90 \%$ purity of HCs in the fluorescence-positive population and no fluorescent cells in the negative population (data not shown). We compared the expression value of each individual probe between the two cell populations (Fig. 2H; Materials and Methods). The established HC markers were found to be highly enriched in the fluorescencepositive (i.e., HC) population (Fig. $2 \mathrm{H}$, genes $1-10$ in the table, red circles), while the established markers for cochlear supporting cells were highly enriched in the negative population (Fig. $2 H$, genes $11-17$ in the table, green circles). This result confirmed the validity and sensitivity of our experimental method.

From the analysis of a selected list of axon guidance molecules and morphogens, we found that Slit molecules, in particular Slit2, stood out as a top candidate potentially involved in regulating the spatial patterning of SGNs, as they were highly enriched in the nonsensory cell population (Fig. 2I).

\section{Expression pattern of Slit in the developing cochlea}

To verify the expression of Slit genes in the cochlea, we performed in situ hybridization for all three Slit genes in the whole-mount cochlea (see Materials and Methods). At E16, strong Slit1 signals were found in the SG (Fig. $2 J, M$ ). On the other hand, strong Slit2 signals were located in the spiral limbus (SL) as well as part of the greater epithelial ridge (GER or Kolliker's organ) region (Fig. $2 \mathrm{~K}, N)$. Slit3 expression was located in similar regions as Slit2 although the signal was weaker (Fig. $2 \mathrm{~L}, \mathrm{O}$ ). These data are largely in agreement with our microarray data at postnatal stages as well as the previous descriptions of Slit expression patterns in the chick and mouse cochlea (Holmes et al., 1998; Yuan et al., 1999; Holmes and Niswander, 2001; Marillat et al., 2002; Webber and Raz, 2006; Battisti and Fekete, 2008; Shared Harvard Inner-Ear Laboratory Database, https://shield.hms.harvard.edu/).

\section{Defects in SGN positioning in the Slit2 mutant}

To elucidate the roles of different Slit molecules in the cochlear development, we first examined the innervation pattern between SGNs and HCs at E18. In the wild-type animal, SGN cell bodies were well restricted in the Rosenthal's canal close to the modiolus, and their peripheral neurites were bundled into RFs to innervate both the inner HCs and outer HCs (Fig. 3A-C). In Slit2 ${ }^{-/-}$embryos (Fig. 3G-I), a significant number of SGN cell bodies were not restrained within the Rosenthal's canal but ectopically distributed (red arrows). The neurites of these mispositioned SGNs mostly traveled along the longitudinal axis and appeared not to innervate HCs (Fig. 3G-I, white arrows). Noticeably, the majority of SGNs were located correctly within the Rosenthal's canal (Fig. 3G), and their peripheral neurites innervated HCs correctly. This is evidenced by the normal organization of type I and II fibers (Fig. $3 P-R$, compared with wild type in $M-O$ ), which innervate inner and outer HCs respectively (Appler and Goodrich, 2011), although some overshooting fibers originating from the mispositioned SGNs were seen. The 3D reconstruction of confocal image stacks showed that the cell bodies of those individually misplaced neurons were located in the space dorsal to the cochlear sensory epithelium along the pathway of SGN-HC projections (Fig. 4P-R). Such mispositioning of SGNs was not observed in $S$ Sit $1^{-1-}$ (Fig. 3D-F) or Slit3 ${ }^{-1-}$ cochlea (Fig. 3J-L). We quantified the number of mispositioned SGNs per cochlea (Fig. 3S). Only Slit $2^{-/-}$mutants exhibited mispositioned SGNs.

Since Slit molecules have been shown to regulate axon fasciculation (Jaworski and Tessier-Lavigne, 2012), we also quantified the fasciculation of RFs (see Materials and Methods). Overall there was no significant difference in the fasciculation pattern 

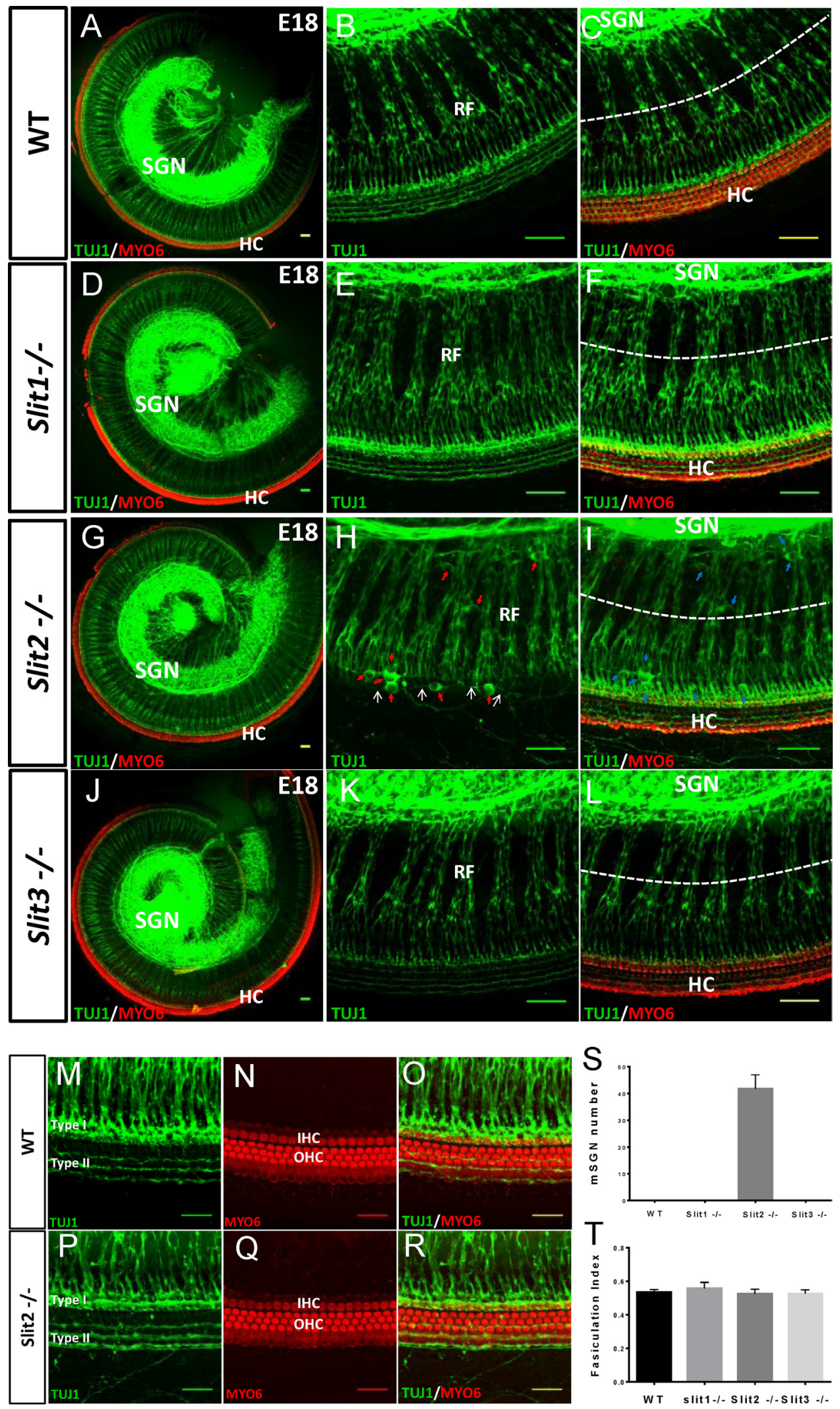

Figure 3. Mispositioned SGNs in the Slit2 mutant cochlea at E18. A-L, Representative images of SGN (green, TUJ1 staining) innervation of HCs (red, Myo6 staining) in the whole-mount cochlea of wild-type, $\mathrm{Slit1}^{-1-}$, Slit2 ${ }^{-1-}$, and Slit3 ${ }^{-1-}$ embryos, as labeled. Images in middle and right panels are higher-magnification images, representing TUJ1 staining and superimposed TUJ1 and My06 staining respectively. Note that $H$ is the projection of a subset of $z$-stack images, not including $\mathrm{HCl}$ layers to show more clearly the mispositioned SGNs (mSGNs), while the other images are the projections of the complete 2 -stack images. Red and blue arrows (in $\boldsymbol{H}$ and / respectively) point to the mSGNs in the Slit2 ${ }^{-1-}$ cochlea, and white arrows (in $\boldsymbol{H}$ ) point to the misrouted neurites originated from the mSGNs. Scale bar, $50 \mu \mathrm{m}$. Enlarged images were taken with a $40 \times$ oil objective (numerical aperture 1.30). $\boldsymbol{M - O}$, Example images of $\mathrm{SGN}$ fibers (green) and HCs (red) and their superimposed image of a wild-type cochlea. $\boldsymbol{P}$ - $\boldsymbol{R}$, example images of a Slit2 ${ }^{-\prime-}$ cochlea. Scale bar, $25 \mu \mathrm{m}$. S, Average number of mSGNs per cochlea for wild-type and different Slit mutant mice. Bar $=S D . N=6$ embryos for all genotypes. $T$, Average fasciculation index (quantified as the ratio of the total thickness of RF bundles over the total width along the white dotted line shown in $C, F, I$, and $L$. Bar $=S D . N=6$ embryos for all genotypes. 

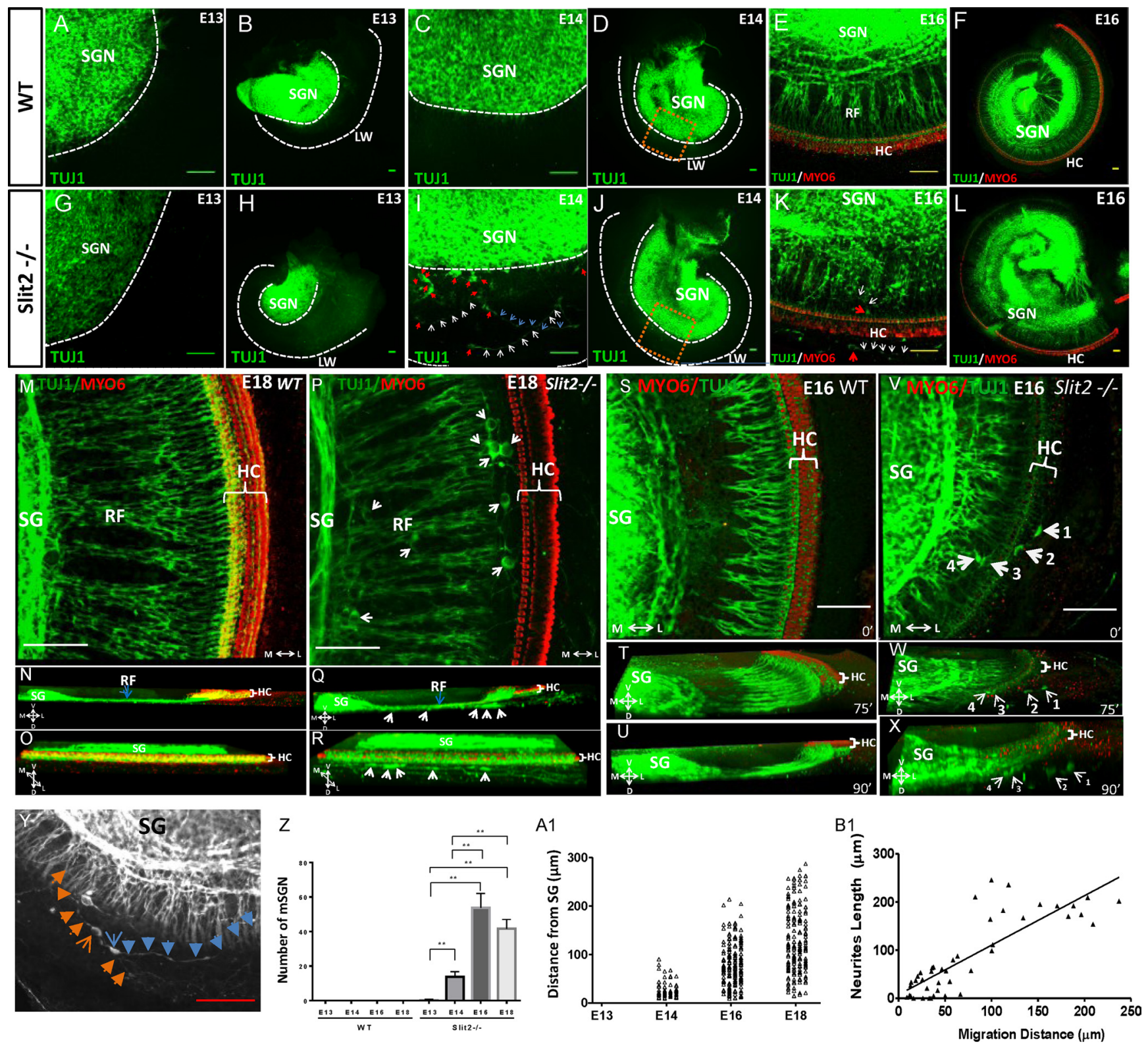

Figure 4. Developmental changes of SGN positioning in the Slit2 mutant cochlea. $\boldsymbol{A}-\boldsymbol{L}$, Representative images of SGN positioning in wild-type $(\boldsymbol{A}-\boldsymbol{F})$ and Slit2 ${ }^{-\prime-}(\boldsymbol{G}-\boldsymbol{L})$ embryos at E13, E14, and $E 16$ as labeled. Both the whole-mount cochleae $(\boldsymbol{B}, \boldsymbol{D}, \boldsymbol{F}, \boldsymbol{H}, \boldsymbol{J}, \boldsymbol{L})$ and high magnification of their local regions $(\boldsymbol{A}, \boldsymbol{C}, \boldsymbol{E}, \boldsymbol{G}, \boldsymbol{I}, \boldsymbol{K})$ are shown. White dotted lines mark the lateral boundary of the $S G N$ cluster and the cochlear lateral wall (LW). Red arrows in I and $\boldsymbol{K}$ mark the mispositioned SGN (mSGN) soma, and white and blue arrows point to the misrouted neurites originated from these neurons. Scale bar, $50 \mu \mathrm{m} . M-\boldsymbol{X}, 3 \mathrm{D}$ reconstruction of images from the wild-type and Slit2 ${ }^{-1-}$ cochleae at E18 and E16. $\boldsymbol{M}-\mathbf{0}$, Top, transverse, and sagittal views of the same $3 \mathrm{D}$ image of an E18 cochlea. $\mathbf{S}-\boldsymbol{U}$ : Top view, $75^{\circ}$ and $90^{\circ}$ turning transverse view. $\boldsymbol{P}-\boldsymbol{R}$ and $\boldsymbol{V}-\boldsymbol{X}$ are presented similarly as $\boldsymbol{M}-\boldsymbol{O}$ and $\mathbf{S} \boldsymbol{U}$, respectively. $\boldsymbol{V}-\boldsymbol{X}, 3 \mathrm{D}$ reconstruction from a subset of $z$-stack images (not including the majority of HClayers) to better illustrate the cell body positions of the $\mathrm{mSGNs}$. White arrows in $\boldsymbol{P}-\boldsymbol{R}$ and $\boldsymbol{V}-\boldsymbol{X}$ mark the mSGNs in Slit2 ${ }^{-/-}$cochlea visualized from different angles. The same numbers in $\boldsymbol{V}$ - $\boldsymbol{X}$ represent the same $\mathrm{mSGNs}$. Note that the $\mathrm{mSGNs}$ and their processes were located dorsal to the organ of Corti (marked by HCs). Scale bar, $50 \mu \mathrm{m}$. $\boldsymbol{Y}$, High-magnification image of $\boldsymbol{V}$ to show the misrouted neurites of cell 1 (blue arrows) and 2 (orange arrows) in $\boldsymbol{V}-\boldsymbol{X}$. Scale bar, $50 \mu \mathrm{m}$. $\boldsymbol{Z}$, Average number of mSGNs per cochlea in Slit2 mutant and their wild-type littermates at different developmental stages. $N=4,5,5,6,4,4,6,6$ embryos for the genotypes listed from left to right respectively. Bar $=S D .{ }^{* *} p<0.01$, one-way ANOVA with Tukey's multiple-comparisons test. $A 1$, Plot of the migration distance of individual $\mathrm{mSGNs}$ from the SG in Slit2 ${ }^{-1-}$ cochleae at different developmental stages. Triangles arranged in the same column represent individual cells from the same cochlea. B1, Scatter plot of the neurite length of the mSGNs against the migration distance of their soma from the SG. The best-fit linear regression line is shown.

between wild-type animals and Slit mutants (Fig. 3T), although small subtle differences could not be completely excluded. Thus, the mispositioning of SGNs and their mistargeting in the Slit2 mutant is unlikely due to a defasciculation of SGN axons.

Developmental progression of SGNs mispositioning in the Slit2 mutant

We further examined the SGN patterning at different developmental stages in the Slit2 mutant. In E13 wild-type em- bryos, SGNs had migrated out from the otocyst and settled down in Rosenthal's canal (Fig. $4 A, B$ ). No mispositioned SGN was observed in the Slit2 mutant at this stage (Fig. $4 G, H$ ). At E14, in the wild-type littermates, the boundary of the SG remained clean, and some SGNs began to extend peripheral neurites toward the sensory epithelium (Fig. $4 C, D$ ). However, in the Slit2 mutant, a small number of SGNs were found to be separated from the main body of the SG (Fig. $4 I$, J, red arrows). Some of them had already extended neurites of substantial 


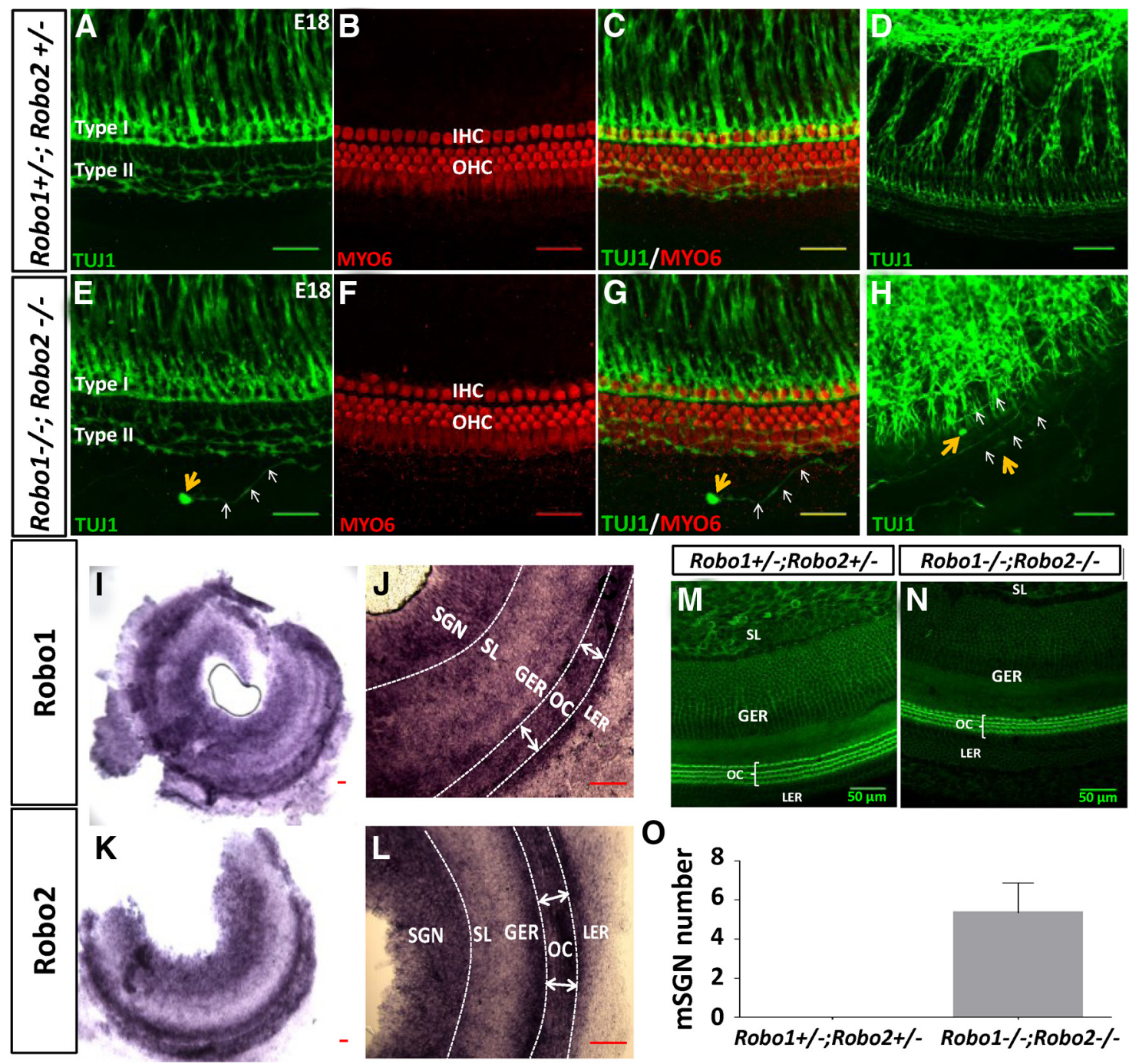

Figure 5. Individually mislocated SGNs in the Robo1/2 mutant. $\boldsymbol{A}-\boldsymbol{H}$, Images of SGN projections and $\mathrm{HCS}$ of two whole-mount cochlea with different genotypes as labeled at E18. $\boldsymbol{D}$ and $\boldsymbol{H}$ are independent examples from $\boldsymbol{A}-\boldsymbol{C}$ and $\boldsymbol{E}-\boldsymbol{G}$, respectively. Yellow arrows in $\boldsymbol{G}$ and $\boldsymbol{H}$ mark the soma of the individually mispositioned SGN (mSGN). Scale bars: $\boldsymbol{A}-\boldsymbol{C}, \boldsymbol{E}-\boldsymbol{G}, 50 \mu \mathrm{m} ; \boldsymbol{D}, \boldsymbol{H}, 25 \mu \mathrm{m}$. $\boldsymbol{H}$ is a projection of a subset of $z$-stack images while $\boldsymbol{A}-\boldsymbol{G}$ are projections of the complete image series. $\boldsymbol{I} \boldsymbol{-} \boldsymbol{L}$, In situ hybridization of Robo 1 and Robo2 in the whole mount-cochlea at E16. $J$ and $\boldsymbol{L}$ are higher magnifications of the cochleae shown in $I$ and $\boldsymbol{K}$, respectively. Double arrowheads in $J$ and $\boldsymbol{L}$ mark the boundary of the organ of Corti (OC). Scale bar, $50 \mu \mathrm{m}$. $\boldsymbol{M}, \boldsymbol{N}$, Top views of the whole-mount cochlea stained with Alexa-488-conjugated phalloidin from a Robo $1^{-1-} ; R_{0 b 02} 2^{-1-}(\boldsymbol{N})$ embryo and its Robo ${ }^{+/-} ;$Robo2 $^{+/-}(\boldsymbol{M})$ littermate at E18. O, Average number of mSGNs per cochlea at E18. $N=4$ embryos for both genotypes.

lengths while some others just started to grow neurites (Fig. 4I, white and blue arrows). At E16, the peripheral neurites of SGNs in wild-type embryos had innervated inner HCs and started to explore outer HCs, with their cell bodies well restricted within the Rosenthal's canal (Fig. 4E,F). In the Slit2 mutant, mispositioned SGNs more distant from the main body of the SG were found (Fig. $4 K, L, V$, red arrows in $K$, white arrows in $V$ ). The $3 \mathrm{D}$ reconstruction of the whole-mount cochlea of the Slit2 mutant further indicated that the mispositioned neurons were consistently located in the space dorsal to the cochlear epithelium, instead of within the cochlear epithelium per se (Fig. $4 V-X$, example for an E16 cochlea). Importantly, the neurites originated from these ectopic SGNs largely extended in the longitudinal direction and were restricted in the space dorsal to the cochlear epithelium without entering the organ of Corti (Fig. $4 P-R, Y$ ).

As shown in the summary, the average number of mispositioned SGNs per cochlea steadily increased from E13 to E16 in the Slit ${ }^{-/-}$mutant (Fig. 4Z). Individual ectopic neurons started to emerge in close proximity to the SG at $\sim$ E14 (Fig. $4 A 1)$. As development progressed, an increasing number of ectopic neurons were observed over a wider range of distances away from the SG (Fig. 4A1). In addition, we found that the ectopic neurons positioned farther away from the SG generally tended to have longer neurites compared with those located closer to the ganglion (Fig. 4B1, $Y$, example neurites extended from the ectopic neurons in $Y$ ), suggesting that as ectopic SGNs drift away from the SG, their neurites progressively elaborate from the soma.

These observations collectively indicate that in the Slit2 mutant, SGNs are dispersed from the SG toward the cochlea epithelium in a progressive manner starting from as early as E14. Based on the fact that Slit2 is strongly expressed in the SL and GER regions close to the cochlear epithelium, our data suggest that Slit2 molecules released from the SL and GER regions provide a 


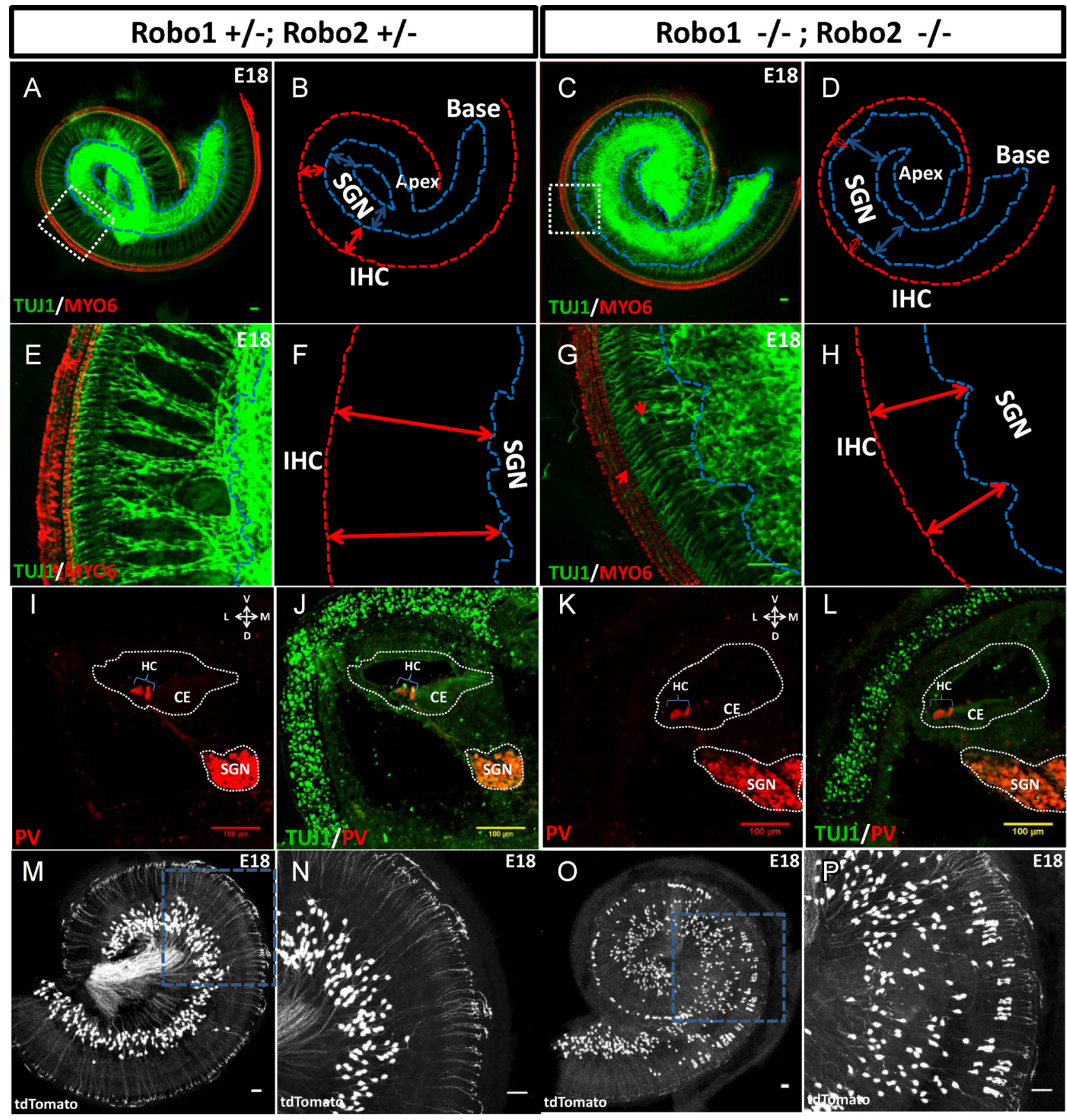

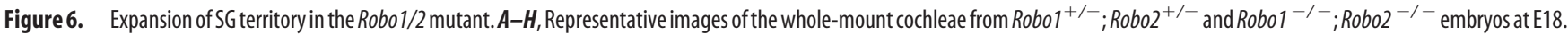
The red lines with double arrowheads illustrate the distance between the lateral SGN boundary and inner HCs (SGN-IHC distance). The blue lines and double arrowheads illustrate the SGN boundary

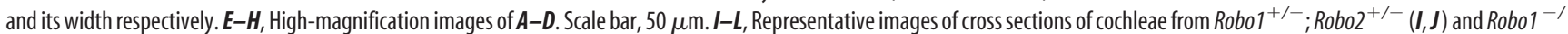
Robo2 $2^{-1-}(\boldsymbol{K}, \boldsymbol{L})$ embryos at E16. White dotted curves mark the boundaries of the SG (SGN) and cochlear epithelium (CE). $\boldsymbol{M}-\boldsymbol{P}$, Representative whole-mount images and their enlarged view (right)

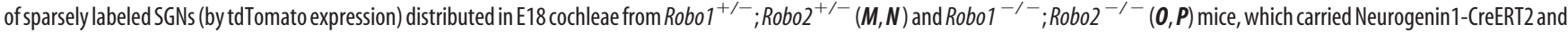
Ai14 alleles. Scale bar, $50 \mu \mathrm{m}$.

restriction force to prevent SGN cell bodies from leaving the Rosenthal's canal while allowing their neurites to extend into the cochlear epithelium.

Expression pattern of Robo in the developing cochleae We next asked whether the effect of Slit2 on SGN positioning is mediated through its Robo receptors. First, we examined whether Robo was expressed in SGNs during the time they innervate HCs by performing in situ hybridization for three Robo genes in the whole-mount cochlea (see Materials and Methods). We found that at E16 both Robo1 and Robo2 were strongly expressed by SGNs as well as the supporting cells in and around the organ of Corti (Fig. 5I-L). We did not detect significant Robo3 expression in the cochlea (data not shown). These expression data suggest that SGNs might depend on Robo1 and Robo2 to interpret the signals of Slit2 secreted from the SL/GER regions. If this is the case, the mutants for Robol and Robo2 should recapitulate the phenotype of the Slit2 mutant. 

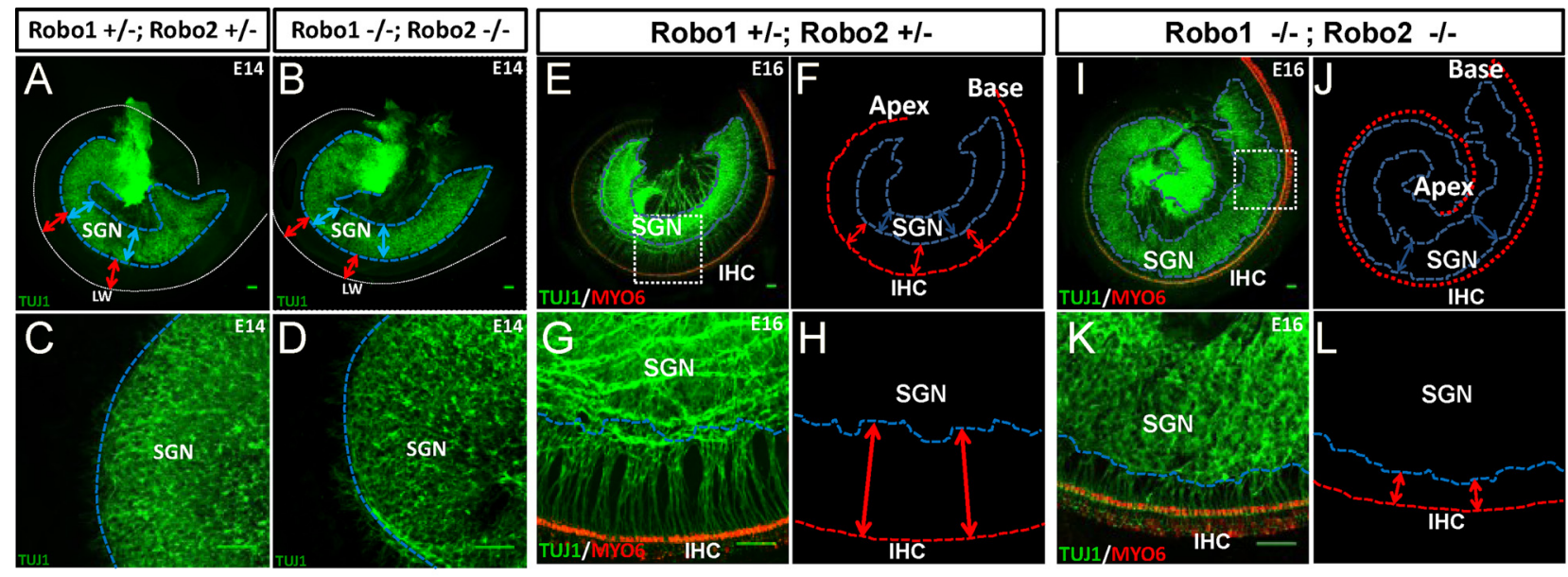

$\mathrm{M}$

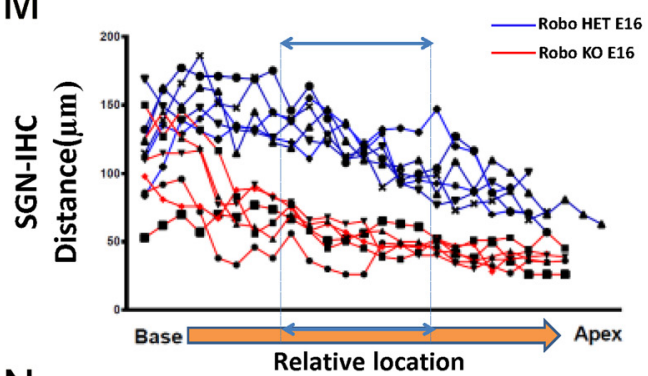

$\mathrm{N}$

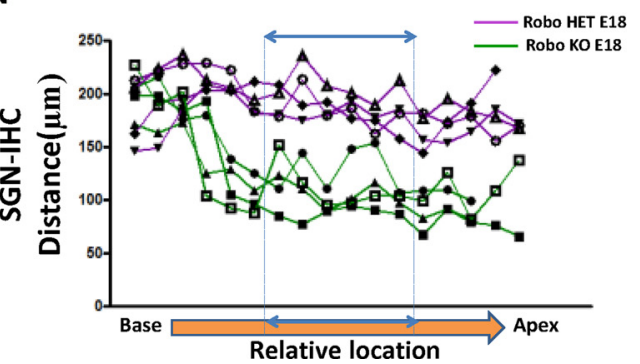

$\mathrm{O}$

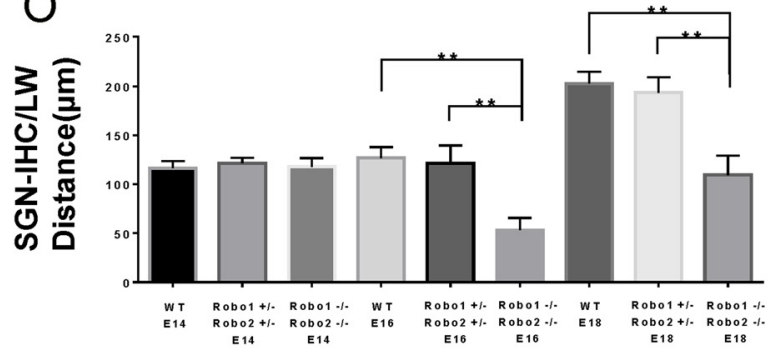

$\mathrm{P}$

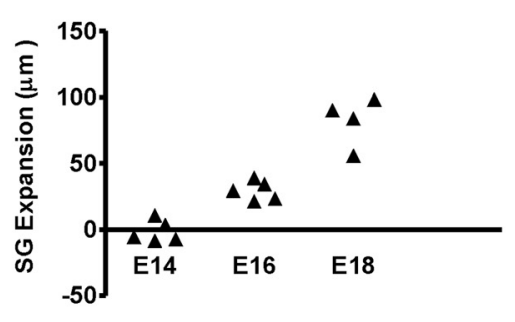

Q

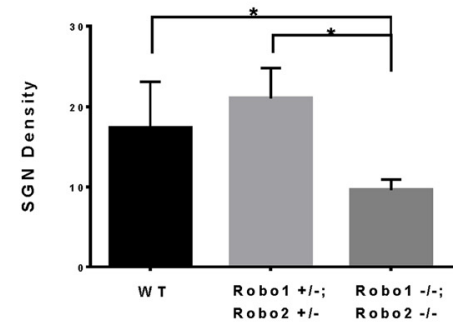

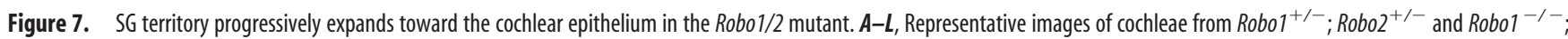
Robo2 ${ }^{-1-}$ embryos at E14 $(\boldsymbol{A}-\boldsymbol{D})$ and E16 $(\boldsymbol{E}-\boldsymbol{L})$ respectively. Labels are applied in a similar way as in Figure 6. Scale bar, $50 \mu \mathrm{m} . \boldsymbol{M}, \mathbf{N}$, Plot of SGN-IHC distance along the base-apex axis of the

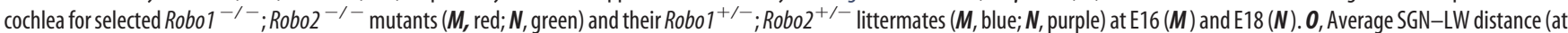
E14) or SGN-IHC distance (atE16 and E18) in the middle part of the cochlea for Robo 1/2 mutants, and their heterozygous and wild-type littermates. $N=5$ embryos for all genotypes at E14 and E16, $N=4$ for all genotypes at E18. Bar $=S D$. ${ }^{* *} p<0.01$, one-way ANOVA with Tukey's multiple-comparisons test. $\boldsymbol{P}$, Quantification of SG expansion in the Robo 1/2 double mutant at different developmental stages (see Materials and Methods for details). Each triangle represents the average expansion distance for a single mutant cochlea as normalized to the wild-type tissue. $\mathbf{Q}$, Average SGN density as quantified by the number of SGNs per 10,000 $\mu \mathrm{m}^{2}$ in wild-type and Robo mutant embryos at E18. $N=4$ embryos for all genotypes. Bar $=S D$. ${ }^{*} p<0.05$, one-way ANOVA with Tukey's multiple-comparison test.

SGN mispositioning in the Robo1/Robo2 double mutant

To address whether Robo1 and Robo2 indeed mediate the Slit2 function, we examined the SGN-HC innervation pattern in Robo1/2 double mutants at E18. A small number of SGNs were found to mislocate in the space dorsal to the cochlear epithelium

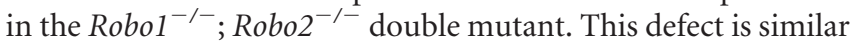
to that found in the Slit2 mutant, but the number of identifiable mispositioned cells was much smaller (Fig. $5 E-H, O$ ). In contrast, no mispositioned SGN was observed in the Robol ${ }^{+/-} ; \mathrm{Robo2}^{+/-}$ littermates (Fig. $5 A-D, O$ ) or wild-type littermates (data not shown). Also similar as in the Slit2 mutant, the neurites of those mispositioned SGNs were misguided and did not innervate $\mathrm{HCs}$ (Fig. $5 E-H$ ). The similarity of the defects found in Slit2 and Robol/2 mutants suggests that Slit2 indeed interacts with Robo1 and Robo2 to ensure the correct positioning of SGN cell bodies.
Since Robos are also expressed in the supporting cells surround the organ of Corti, we examined the structural arrangement of the cochlear epithelium using phalloidin staining (Grimsley-Myers et al., 2009). We did not observe any significant alterations of the overall cochlear structure in Robo1/2 double mutants in comparison with their heterozygous littermates (Fig. $5 M, N$ ) or wild-type littermates (data not shown).

\section{Expansion of SGN boundary in the Robo1/2 double mutant} In the Slit2 mutant, most SGNs are in their normal position with only a small number of cells scattered toward the cochlear epithe-

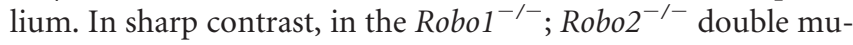
tant at E18, the large population of SGNs, in addition to individually mispositioned SGNs, was not restricted within the Rosenthal's canal any more but shifted toward the sensory epithelium as an entirety (Fig. 6C, D, G,H). This was not observed in 

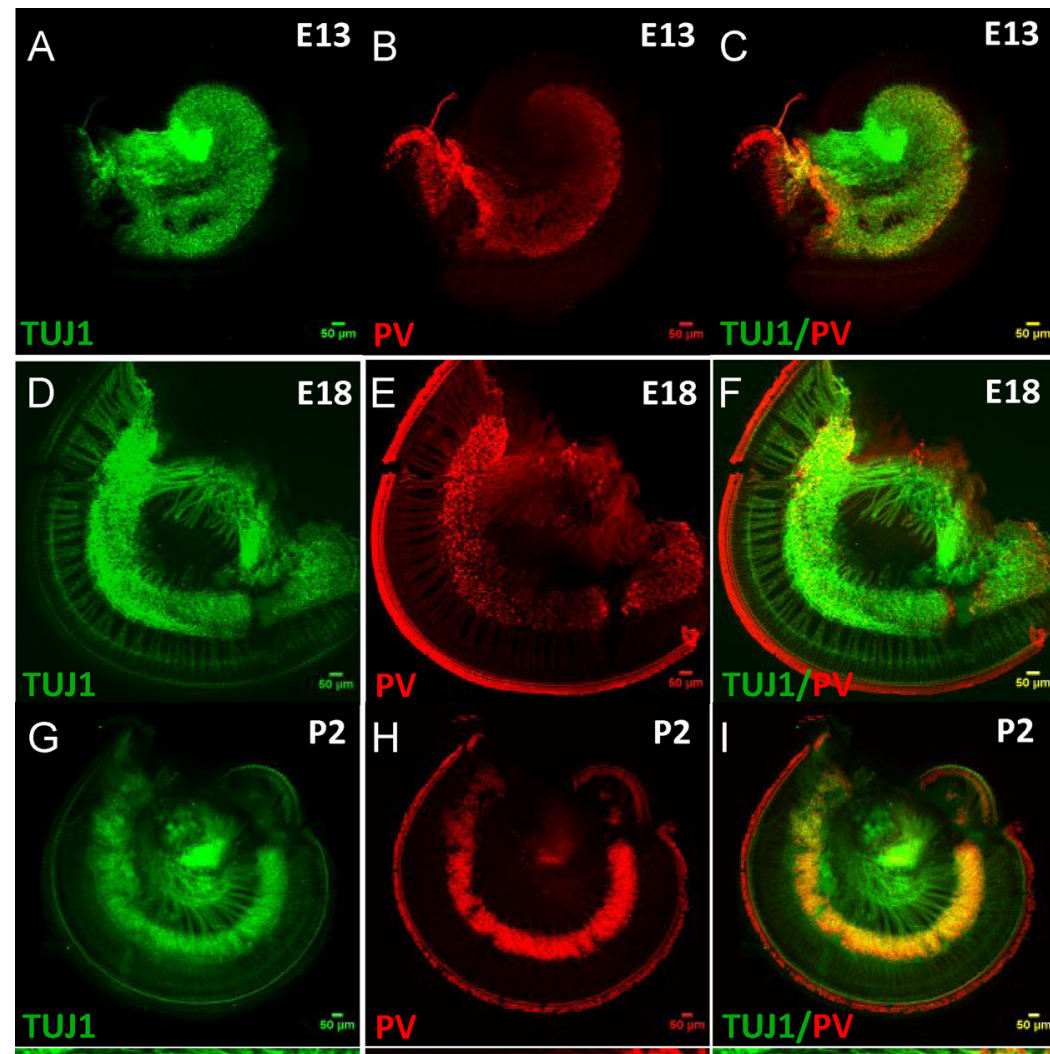

E18
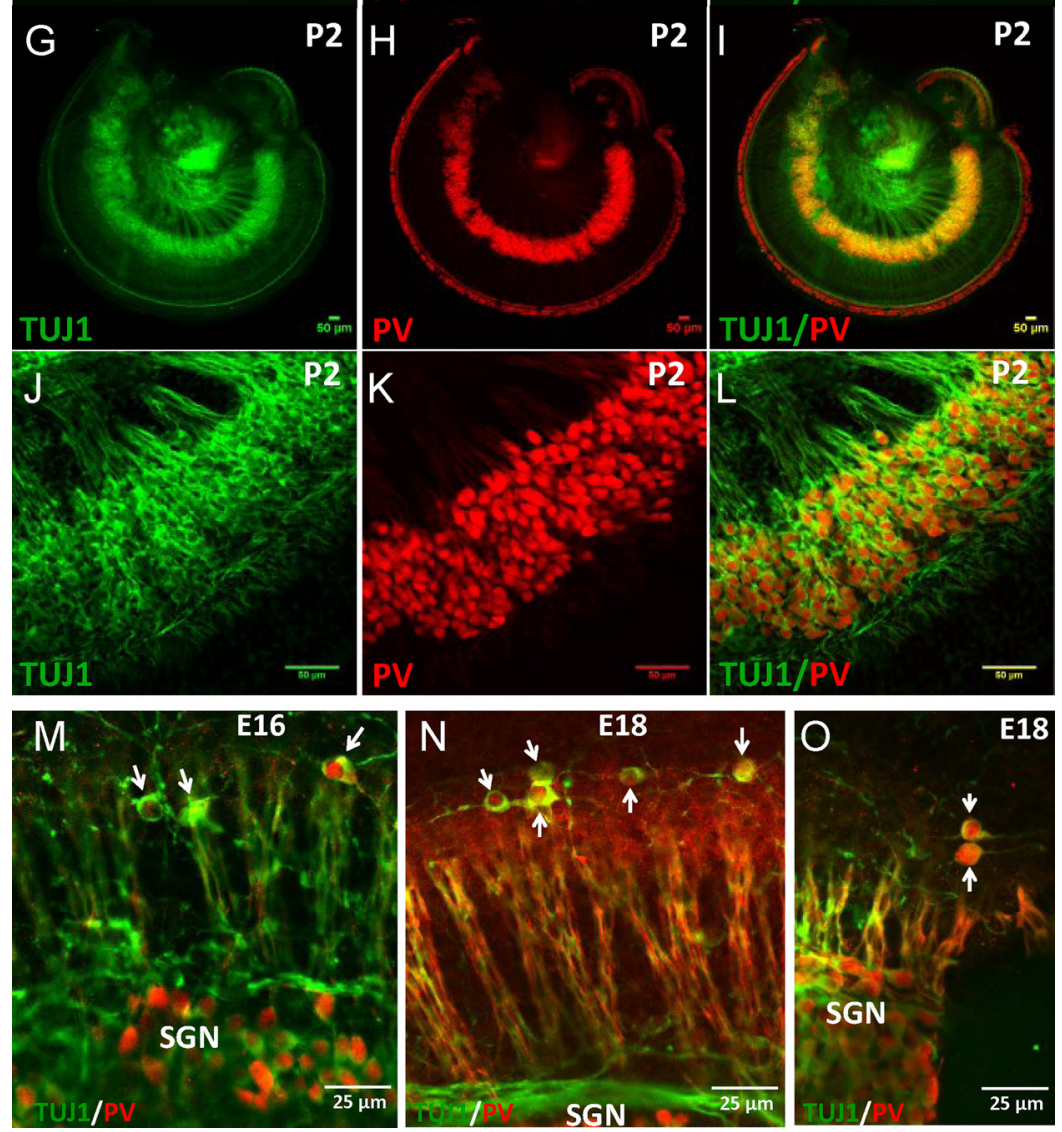

Figure 8. Mispositioned neurons as revealed by PV staining in the Slit2 mutant. $A-I$, Representative images of whole-mount cochleae from wild-type embryos stained with TUJ1 (green) and PV (red) antibodies at E13 (A-C, E18 (D-F), and P2 (G-L). J-L, Enlarged views of SGNs in G-I. Note that SGNs express PV. Scale bar, $50 \mu \mathrm{m} . \boldsymbol{M}-\mathbf{0}$, Representative images of Slit2 ${ }^{-1-}$ cochleae at E16 $(\boldsymbol{M})$ and E18 $(\boldsymbol{N}, \mathbf{0})$. White arrows point to the mispositioned SGNs, which were positive for both TUJ1 and PV staining. Scale bar, $25 \mu \mathrm{m}$.

HCs remained largely unchanged (data not shown). As a result, the width of SG (Fig. $6 B, D$, blue lines with double arrowheads) appeared increased in $\mathrm{Robol}^{-/-}$; Robo2 $2^{-/-}$ embryos in comparison with their Robo1 $^{+/-}$; Robo2 ${ }^{+/-}$littermates. Crossing neurites running in the longitudinal direction without innervating $\mathrm{HCs}$ were observed in the Robo1 $1^{-/-}$; Robo2 $2^{-/-}$mutants (Fig. 6G) but not in their Robol ${ }^{+/-}$; Robo2 ${ }^{+/-}$(Fig. 6E) or wild-type littermates. We did not observe significant difference in SGN-IHC distance, SG width, or SGN-HC projection pattern between the Robo1 ${ }^{+/-}$; Robo2 $2^{+/-}$and wild-type embryos.

We cross-sectioned the cochlear tissue

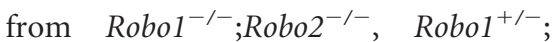
Robo $2^{+/-}$, and wild-type littermates to further analyze the spatial relationship between the SG and the cochlear epithelium. In the Robo1 $1^{-/-}$; Robo2 $2^{-/-}$tissue, the SG extended dramatically toward the cochlear epithelium but had not invaded it yet (Fig. $6 K, L)$. The overall cochlear structural pattern was thus preserved. No difference was observed between Robol $^{+/-} ;$Robo $^{+/-}$ (Fig. 6I,J) and wild-type (data not shown) tissue. These observations are consistent with the results from the whole-mount preparations.

In an independent experiment to verify Robo mutant phenotypes, we genetically labeled SGNs on the Robo mutant background by crossing mouse lines carrying the following alleles: Neurogenin1-CreER (Koundakjian et al., 2007), Ail4 (Madisen et al., 2010), and Robo1 ${ }^{+/-}$; Robo2 $2^{+/-}$. In embryos carrying all the four alleles, SGNs were labeled sparsely by tdTomato expression (Fig. 6M-P), consistent with the previous report (Koundakjian et al., 2007). While the sparsely labeled SGNs were tightly packed in the central cochlea in $\mathrm{Robol}^{+/-} ; \mathrm{Robo}^{+/-}$ (Fig. $6 M, N$ ) or wild-type embryos (data not shown), they were much more dispersed toward the sensory epithelium in Robo1 $^{-/-}$; Robo2 $2^{-/-}$embryos (Fig. 6O,P), consistent with an extension of the lateral SG boundary toward the sensory epithelium (Fig. 6K,L).

\section{Developmental progression of SGN} territory expansion in Robo mutants

the Robo1 ${ }^{+/-}$; Robo2 $2^{+/-}$(Fig. 6A, B,E,F) or wild-type littermates (data not shown). We measured the radial distance between the lateral boundary of the SG and inner HCs (SGN-IHC distance; Fig. $6 B, D, F, H$, red lines with double arrowheads) along the base-apex axis of the entire cochlea (Fig. $7 N$ ). In the middle region of the cochlea, the SGN-IHC distance was significantly reduced in $\mathrm{Robol}^{-/-} ; \mathrm{Robo}^{-/-}$embryos compared with Robo1 $^{+/-}$; Robo2 ${ }^{+/-}$or wild-type littermates (Fig. 7O), while the total radial distance from the medial boundary of the SG to inner
We also performed developmental studies to determine when the expansion of SG boundary occurred in Robo1/2 double mutants. At E14, SGNs were normally located in the central cochlea in both Robo1 $^{+/-}$; Robo2 $2^{+/-}$(Fig. 7 A,C) and Robo1 ${ }^{-/-}$; Robo2 $2^{-/-}$(Fig. $7 B, D$ ) embryos, compared to wild-type embryos (data not shown). There was no significant difference in the radial distance from the lateral SG boundary to the lateral wall (SGN-LW distance; Fig. $7 A, B$, red lines with double arrowheads) or SG width (Fig. $7 A, B$, blue lines with double arrowheads) between wild- 
E14

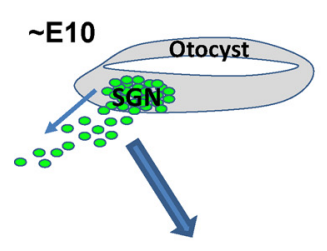

E13.5

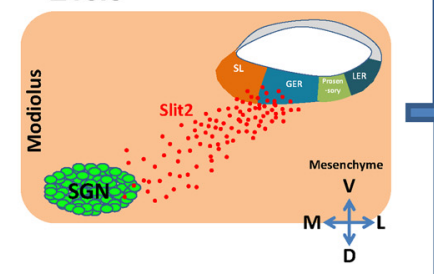

E16/E18
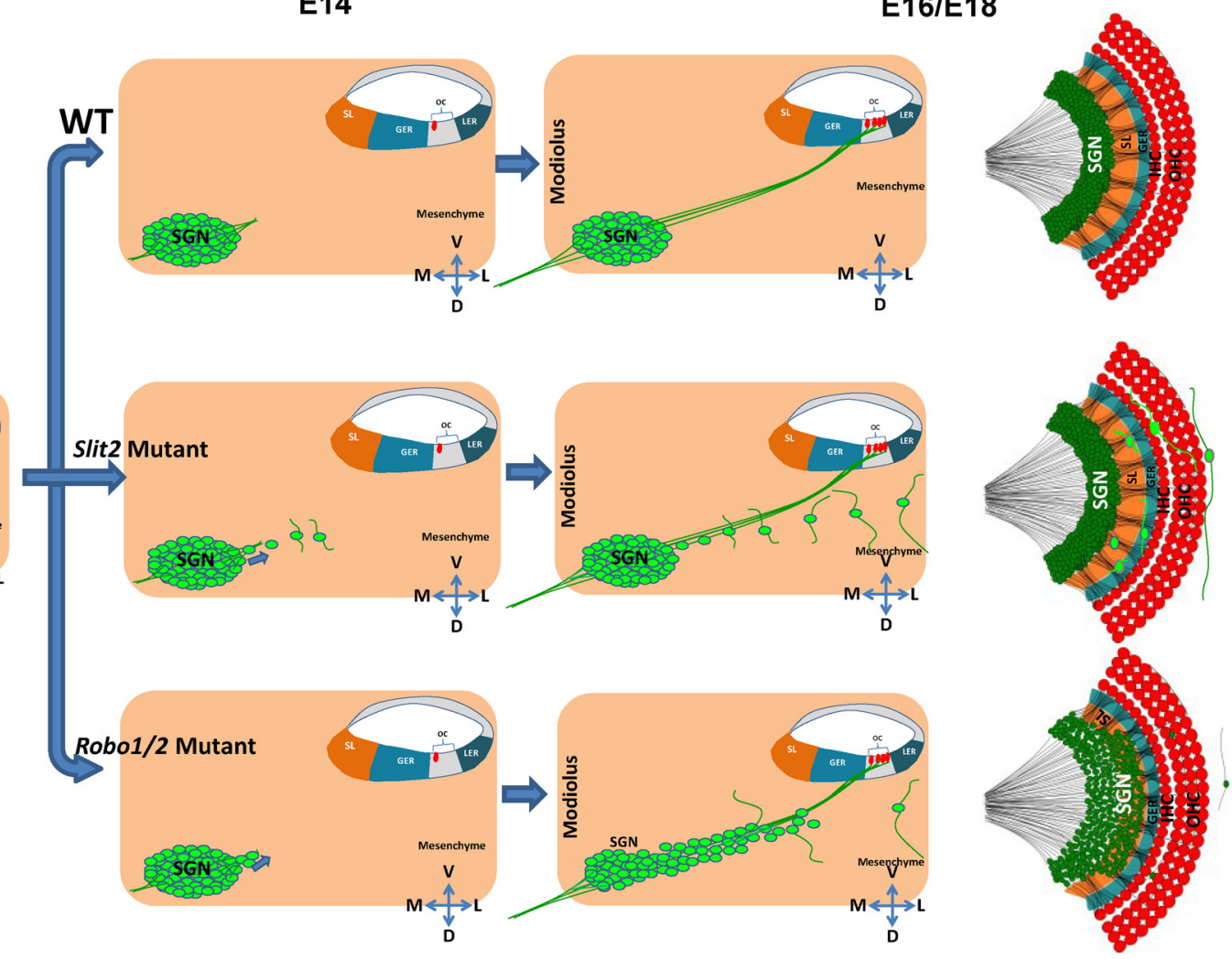

Figure 9. A proposed model for Slit/Robo signaling in restricting SGN positioning. Early in development ( E10), SGNs delaminate from the otocyst, migrate toward the modiolus, and settle down in the Rosenthal's canal by E13.5. Subsequently, SGNs extend their peripheral axons toward the organ of Corti (OC) at E14 and begin to form synaptic connections with HCs at E16. The SGN somas are restrained within the Rosenthal's canal during the formation of SGN-HC innervations in the wild-type cochlea. Slit2 (and possibly Slit3) secreted from the SL and GER regions acts on Robo receptors expressed in SGNs and provides the restriction force to restrain SGNs from migrating toward the cochlear epithelium. In the Slit2 mutant cochlea, a number of SGNs disperse from the Rosenthal's canal progressively and were eventually located in the space dorsal to the cochlear epithelium. During this process, their neurites progressively extend out from the soma and largely travel along the longitudinal direction and appear not to innervate HCs. In the Robo mutant, a small number of SGNs are scattered dorsal to the cochlear epithelium similarly as in the Slit2 mutant. In addition, the entire SGN territory expands progressively toward the cochlear epithelium starting from E14, resulting in a shorter SGN-HC distance as well as a broader SGN width. The more severe defect in the Robo mutant compared with the Slit2 mutant suggests that additional factors act synergistically with Slit2 on Robo receptors to restrict the SGN soma within the Rosenthal's canal, which is essential for the formation of precise patterning of SGN-HC connections.

type, Robo1 ${ }^{+/-}$; Robo2 $2^{+/-}$, and Robo1 ${ }^{-/-}$; Robo2 $2^{-/-}$embryos (Fig. $7 O$ and data not shown, respectively). These results suggest that the initial migration of SGNs from the otocyst and their settlement in the Rosenthal's canal are not altered in the Robo1/2 mutant. At E16, however, the SGN-IHC distance was significantly shorter in Robo1 ${ }^{-1-}$; Robo2 $2^{-1-}$ mutants in comparison with $\mathrm{Robo1}^{+/-}$; Robo2 $2^{+/-}$(Fig. 7E-L,M,O) or wild-type littermates. At the same time, the SG width became broader in the Robo mutants in comparison with their heterozygous or wildtype littermates (data not shown). We quantified the distance for SG expansion in the Robo1/2 mutant across developmental stages and found that SG lateral boundary progressively shifted toward the cochlear epithelium (Fig. 7P). Also consistent with the notion of SG expansion, SGN density was significantly reduced in Robo1 $^{-1-} ;$ Robo2 $^{-1-}$ embryos in comparison with their $\mathrm{Robo1}^{+/-} ; \mathrm{Robo2}^{+/-}$or wild-type littermates as examined at E18 (Fig. 7Q). Together, our data indicate that, in Robo mutants, the entire SGN territory is expanded progressively toward the sensory epithelium after the initial migration and settlement of SGNs is accomplished, similar to the developmental progression of the defect found in the Slit2 mutant.

\section{Discussion}

The assembly of cochlear circuits follows discrete steps during embryonic development. The specific pattern of cochlear inner- vations provides a good model to examine molecular mechanisms underlying the local organization of different cell populations and their interactions. Using this model, our study revealed a molecular mechanism that is critical for the control of the cochlear patterning at early developmental stages. Our genetic analysis has revealed a novel functional role of Slit-Robo signaling: to restrict spatial positioning of periphery neurons, i.e., to stabilize the position of SGNs in the Rosenthal's canal and to prevent them from migrating out abnormally during the assembly of peripheral auditory circuits.

\section{Potential origin of the mispositioned neurons}

Several lines of evidence support the idea that that the mispositioned neurons are abnormally migrated SGNs. First, the mispositioned neurons expressed the same markers as the rest of SGNs. In addition to TUJ1, we also identified PV as an early marker for SGNs. As shown by Figure 8 , staining with the antibody to PV revealed SGN soma positioning similarly as TUJ1 staining across developmental stages, starting as early as E13. The individually mispositioned neurons in the Slit2 mutant were consistently labeled by PV staining, which overlapped with TUJ1 staining (Fig. 8M-O), further supporting the idea that the mispositioned neurons express the same markers as the other SGNs. In addition, mispositioned neurons in Robo1/2 mutants also express neurogenin 1 as other SGNs. Second, the mispositioned neurons were mostly located along the SG-HC 
projections (especially in Robo mutants) dorsal to the cochlear epithelium, but not inside the epithelium, as shown by the 3D images of the whole-mount cochlea as well as the images of transverse sections. This argues against the possibility that the mispositioned neurons are generated de novo in the cochlear epithelium, although the cells there (e.g., in Kolliker's organ) are capable of being converted to neurons (Puligilla et al., 2010) and Slit/Robo signaling has been shown to modulate neurogenesis (Borrell et al., 2012). Third, the spatial and temporal pattern of the mispositioned neurons further supports the idea that such neurons originate from the SG. In the Slit2 mutant, individual ectopic neurons start to emerge in close proximity to the SG at $\sim$ E14 (Fig. $4 I, A 1$ ). As development progresses, ectopic neurons are increased in number with some cells located farther away from the ganglion (Fig. 4A1). This is consistent with the notion that more and more SGNs are migrating out of the ganglion and toward the lateral wall. In the Robo1/2 mutant, the lateral expansion of the SG starts $\sim$ E14 and proceeds progressively over time (Fig. 7P). Furthermore, we found that ectopic neurons located farther away from the SG (i.e., more laterally located) generally have longer neurites compared with those located closer to the ganglion (Fig. 4B1), suggesting that neurites progressively elaborate from the soma after the neurons migrate out of the ganglion. Together these results are consistent with a concept that the mispositioned cells are progressively dispersed from the SG.

\section{Molecular cues for SGN positioning}

Previously it was reported that in ErbB2 mutant mice SGNs migrate beyond their normal position and settle down abnormally in the modiolus (Morris et al., 2006). Here we found that after the initial migration is accomplished, SGNs are progressively dispersed toward the sensory epithelium as an entirety in Robo mutants and to a lesser degree are dispersed as individual cells in Slit2 mutants (Fig. 9). It is likely that Slit/Robo and ErbB2 signaling prevents SGNs from escaping into the cochlear epithelium and modiolus respectively, thus ensuring their precise spatial patterning. Indicated by its expression pattern, Slit2 is likely secreted from the SL and GER regions, setting up the lateral boundary of the SG. Since Slit is not the only ligand for Robo (Ypsilanti et al., 2010), the massive expansion of SGN territory in Robo mutants but not in Slit2 mutants (Fig. 9) suggests that other Robo ligands might act synergistically with Slit2 to impose the restriction force so as to maintain a compact SGN cluster. Thus, by restricting the SGN positioning, Slit/Robo signaling can maintain a clear spatial segregation between SGNs and their target tissue, the cochlear sensory epithelium. This separation ensures the compartmentalization of distinct cell populations and prevents them from intermingling into a scrambled organization in the cochlea. Such molecular function is reminiscent of the restriction of cell intermingling between hindbrain segments by the interaction of Eph receptors and their Ephrin ligand (Mellitzer et al., 1999; Xu et al., 2000).

\section{Spatial positioning mediated by Slit/Robo signaling}

Previous studies suggest that both contact-dependent cell-cell interactions (e.g., through Ephrin-Eph receptors; Mellitzer et al., 1999) and extracellular cues, such as Reelin (Marín and Rubenstein, 2003; Frotscher, 2010), play important roles in regulating the migration or spatial positioning of cells. In the developing inner ear, specific expression of axon guidance molecules were revealed previously (Webber and Raz, 2006; Fekete and Campero, 2007; Appler and Goodrich, 2011), but their potential roles in the development of spatial organization of cochlear cells have not been examined. Axon guidance molecules are important in determining neuronal innervation patterns in both peripheral nervous systems and CNSs (Tessier-Lavigne, 2002; Yamamoto et al., 2002; Huberman et al., 2008; Salinas and Zou, 2008; Cho et al., 2009; Shen and Cowan, 2010). Of the guidance molecules, Slits are of particular interest as they have been shown to play essential roles in various processes, such as axon guidance, branching, and fasciculation, as well as cell migration through the Robo receptors (Brose et al., 1999; Kidd et al., 1999; Wang et al., 1999; Ma and Tessier-Lavigne, 2007; Ypsilanti et al., 2010; Xiao et al., 2011). Their function in the inner ear development and patterning is not known. To our knowledge, this is the first demonstration that Slit/Robo signaling plays an essential role in shaping the spatial patterning of distinct cell populations in the nervous system. The correct assembly and positioning of SGN cell bodies appears critical for their afferent axons to navigate to HCs without errors. As shown in both Slit2 and Robol/2 mutants, the neurites of the individually mispositioned neurons travel randomly and appear not to innervate HCs. Interestingly, in Robo1/2 mutants, most of laterally displaced cells within the main body of the SG can still make correct innervations of HCs, although we did observe increased frequency of crossing fibers. One possibility is that the axons of dispersed neurons within the body of SGs are able to follow the path provided by the axon fascicles from the normally positioned neurons, due to their close proximity to those axon fascicles, while those individually mispositioned neurons may be too far apart for their axons to join the normal axon fascicles. In addition, the misrouted axons from the mispositioned neurons suggest that the guidance cues for SG-HC neurite pathfinding are not present in the ectopic locations. The in situ results suggest that Slit molecules are expressed in SGNs, especially Slit1. Since we did not observe any abnormality in Slit1 mutant, the role of SGN-expressed Slit molecules remains to be elucidated. Microarray data also suggest that Slit is expressed at postnatal stages. Whether Slit/Robo signaling exerts at these stages the same function of spatially restricting SGNs or plays additional roles remains to be investigated in the future. Together, the spatially precise positioning of SGN cell bodies by Slit/Robo interactions may provide an essential control for the formation of precise cochlear innervations.

\section{Notes}

Supplemental material for this article is available at https://sites.google. $\mathrm{com} /$ site/slitrobozhanglab/. Included in the website are four movies of the confocal $Z$-stack images spanning the entire depth of the E18 cochlea. Movies show, for example, images of wild type, Slit 2 mutant, and Robo1/2 Het cochleae, as well as images of Robo1/2 mutant cochlea. One movie shows rotating views of a $3 \mathrm{D}$ reconstructed image from an example Slit2 mutant cochlea. This material has not been peer reviewed.

\section{References}

Appler JM, Goodrich LV (2011) Connecting the ear to the brain: Molecular mechanisms of auditory circuit assembly. Prog Neurobiol 93:488-508. CrossRef Medline

Battisti AC, Fekete DM (2008) Slits and Robos in the developing chicken inner ear. Dev Dyn 237:476-484. CrossRef Medline

Bolstad BM, Irizarry RA, Astrand M, Speed TP (2003) A comparison of normalization methods for high density oligonucleotide array data based on variance and bias. Bioinformatics 19:185-193. CrossRef Medline

Borrell V, Cárdenas A, Ciceri G, Galcerán J, Flames N, Pla R, Nóbrega-Pereira S, García-Frigola C, Peregrín S, Zhao Z, Ma L, Tessier-Lavigne M, Marín O (2012) Slit/Robo signaling modulates the proliferation of central nervous system progenitors. Neuron 76:338-352. CrossRef Medline

Brose K, Bland KS, Wang KH, Arnott D, Henzel W, Goodman CS, TessierLavigne M, Kidd T (1999) Slit proteins bind Robo receptors and have an evolutionarily conserved role in repulsive axon guidance. Cell 96:795-806. CrossRef Medline

Cho JH, Prince JE, Cloutier JF (2009) Axon guidance events in the wiring of 
the mammalian olfactory system. Mol Neurobiol 39:1-9. CrossRef Medline

Coate TM, Raft S, Zhao X, Ryan AK, Crenshaw EB 3rd, Kelley MW (2012) Otic mesenchyme cells regulate spiral ganglion axon fasciculation through a Pou3f4/EphA4 signaling pathway. Neuron 73:49-63. CrossRef Medline

Doetzlhofer A, White P, Lee YS, Groves A, Segil N (2006) Prospective identification and purification of hair cell and supporting cell progenitors from the embryonic cochlea. Brain Res 1091:282-288. CrossRef Medline

Efron B, Tibshirani R (2007) On testing the significance of sets of genes. Ann Appl Stat 1:107-129. CrossRef

Fekete DM, Campero AM (2007) Axon guidance in the inner ear. Int J Dev Biol 51:549-556. CrossRef Medline

Fritzsch B, Matei VA, Nichols DH, Bermingham N, Jones K, Beisel KW, Wang VY (2005) Atoh1 null mice show directed afferent fiber growth to undifferentiated ear sensory epithelia followed by incomplete fiber retention. Dev Dyn 233:570-583. CrossRef Medline

Frotscher M (2010) Role for Reelin in stabilizing cortical architecture. Trends Neurosci 33:407-414. CrossRef Medline

Gale JE, Marcotti W, Kennedy HJ, Kros CJ, Richardson GP (2001) FM1-43 dye behaves as a permeant blocker of the hair-cell mechanotransducer channel. J Neurosci 21:7013-7025. Medline

Géléoc GS, Holt JR (2003) Developmental acquisition of sensory transduction in hair cells of the mouse inner ear. Nat Neurosci 6:1019-1020. CrossRef Medline

Grieshammer U, Le M, Plump AS, Wang F, Tessier-Lavigne M, Martin GR (2004) SLIT2-mediated ROBO2 signaling restricts kidney induction to a single site. Dev Cell 6:709-717. CrossRef Medline

Grimsley-Myers CM, Sipe CW, Géléoc GS, Lu X (2009) The small GTPase Rac1 regulates auditory hair cell morphogenesis. J Neurosci 29: 15859-15869. CrossRef Medline

Groves AK, Fekete DM (2012) Shaping sound in space: the regulation of inner ear patterning. Development 139:245-257. CrossRef Medline

Hippenmeyer S, Vrieseling E, Sigrist M, Portmann T, Laengle C, Ladle DR, Arber S (2005) A developmental switch in the response of DRG neurons to ETS transcription factor signaling. PLoS Biol 3:e159. Medline

Holmes G, Niswander L (2001) Expression of slit-2 and slit-3 during chick development. Dev Dyn 222:301-307. CrossRef Medline

Holmes GP, Negus K, Burridge L, Raman S, Algar E, Yamada T, Little MH (1998) Distinct but overlapping expression patterns of two vertebrate slit homologs implies functional roles in CNS development and organogenesis. Mech Dev 79:57-72. CrossRef Medline

Huberman AD, Feller MB, Chapman B (2008) Mechanisms underlying development of visual maps and receptive fields. Annu Rev Neurosci 31: 479-509. CrossRef Medline

Jaworski A, Tessier-Lavigne M (2012) Autocrine/juxtaparacrine regulation of axon fasciculation by Slit-Robo signaling. Nat Neurosci 15:367-369. CrossRef Medline

Kelley MW (2006) Regulation of cell fate in the sensory epithelia of the inner ear. Nat Rev Neurosci 7:837-849. CrossRef Medline

Kelly MC, Chen P (2009) Development of form and function in the mammalian cochlea. Curr Opin Neurobiol 19:395-401. CrossRef Medline

Kidd T, Bland KS, Goodman CS (1999) Slit is the midline repellent for the robo receptor in Drosophila. Cell 96:785-794. CrossRef Medline

Koundakjian EJ, Appler JL, Goodrich LV (2007) Auditory neurons make stereotyped wiring decisions before maturation of their targets. J Neurosci 27:14078-14088. CrossRef Medline

Lelli A, Asai Y, Forge A, Holt JR, Géléoc GS (2009) Tonotopic gradient in the developmental acquisition of sensory transduction in outer hair cells of the mouse cochlea. J Neurophysiol 101:2961-2973. CrossRef Medline

Lu CC, Appler JM, Houseman EA, Goodrich LV (2011) Developmental profiling of spiral ganglion neurons reveals insights into auditory circuit assembly. J Neurosci 31:10903-10918. CrossRef Medline

Ma L, Tessier-Lavigne M (2007) Dual branch-promoting and branchrepelling actions of Slit/Robo signaling on peripheral and central branches of developing sensory axons. J Neurosci 27:6843-6851. CrossRef Medline

Madisen L, Zwingman TA, Sunkin SM, Oh SW, Zariwala HA, Gu H, Ng LL, Palmiter RD, Hawrylycz MJ, Jones AR, Lein ES, Zeng H (2010) A robust and high-throughput Cre reporting and characterization system for the whole mouse brain. Nat Neurosci 13:133-140. CrossRef Medline

Marillat V, Cases O, Nguyen-Ba-Charvet KT, Tessier-Lavigne M, Sotelo C,
Chédotal A (2002) Spatiotemporal expression patterns of slit and robo genes in the rat brain. J Comp Neurol 442:130-155. CrossRef Medline

Marín O, Rubenstein JL (2003) Cell migration in the forebrain. Annu Rev Neurosci 26:441-483. CrossRef Medline

Mellitzer G, Xu Q, Wilkinson DG (1999) Eph receptors and ephrins restrict cell intermingling and communication. Nature 400:77-81. CrossRef Medline

Meyers JR, MacDonald RB, Duggan A, Lenzi D, Standaert DG, Corwin JT, Corey DP (2003) Lighting up the senses: FM1-43 loading of sensory cells through nonselective ion channels. J Neurosci 23:4054-4065. Medline

Morris JK, Maklad A, Hansen LA, Feng F, Sorensen C, Lee KF, Macklin WB, Fritzsch B (2006) A disorganized innervation of the inner ear persists in the absence of ErbB2. Brain Res 1091:186-199. CrossRef Medline

Nayagam BA, Muniak MA, Ryugo DK (2011) The spiral ganglion: connecting the peripheral and central auditory systems. Hear Res 278:2-20. CrossRef Medline

Plump AS, Erskine L, Sabatier C, Brose K, Epstein CJ, Goodman CS, Mason CA, Tessier-Lavigne M (2002) Slit1 and Slit2 cooperate to prevent premature midline crossing of retinal axons in the mouse visual system. Neuron 33:219-232. CrossRef Medline

Puligilla C, Dabdoub A, Brenowitz SD, Kelley MW (2010) Sox2 induces neuronal formation in the developing mammalian cochlea. J Neurosci 30:714-722. CrossRef Medline

Ruben RJ (1967) Development of the inner ear of the mouse: a radioautographic study of terminal mitoses. Acta Otolaryngol 220:1-44.

Sabatier C, Plump AS, Le M, Brose K, Tamada A, Murakami F, Lee EY, Tessier-Lavigne M (2004) The divergent Robo family protein rig-1/ Robo3 is a negative regulator of slit responsiveness required for midline crossing by commissural axons. Cell 117:157-169. CrossRef Medline

Salinas PC, Zou Y (2008) Wnt signaling in neural circuit assembly. Annu Rev Neurosci 31:339-358. CrossRef Medline

Shen K, Cowan CW (2010) Guidance molecules in synapse formation and plasticity. Cold Spring Harb Perspect Biol 2:a001842. CrossRef Medline

Smyth GK (2004) Linear models and empirical Bayes methods for assessing differential expression in microarray experiments. Stat Appl Genet Mol Biol 3:Article3. Medline

Subramanian A, Tamayo P, Mootha VK, Mukherjee S, Ebert BL, Gillette MA, Paulovich A, Pomeroy SL, Golub TR, Lander ES, Mesirov JP (2005) Gene set enrichment analysis: a knowledge-based approach for interpreting genome-wide expression profiles. Proc Natl Acad Sci U S A 102: 15545-15550. CrossRef Medline

Tessier-Lavigne M (2002) Wiring the brain: the logic and molecular mechanisms of axon guidance and regeneration. Harvey Lect 98:103-143. Medline

Wang KH, Brose K, Arnott D, Kidd T, Goodman CS, Henzel W, TessierLavigne M (1999) Biochemical purification of a mammalian slit protein as a positive regulator of sensory axon elongation and branching. Cell 96:771-784. CrossRef Medline

Webber A, Raz Y (2006) Axon guidance cues in auditory development. Anat Rec A Discov Mol Cell Evol Biol 288:390-396. Medline

Xiang M, Gao WQ, Hasson T, Shin JJ (1998) Requirement for Brn-3c in maturation and survival, but not in fate determination of inner ear hair cells. Development 125:3935-3946. Medline

Xiang M, Maklad A, Pirvola U, Fritzsch B (2003) Brn3c null mutant mice show long-term, incomplete retention of some afferent inner ear innervation. BMC Neurosci 4:2. CrossRef Medline

Xiao T, Staub W, Robles E, Gosse NJ, Cole GJ, Baier H (2011) Assembly of lamina-specific neuronal connections by slit bound to type IV collagen. Cell 146:164-176. CrossRef Medline

Xu Q, Mellitzer G, Wilkinson DG (2000) Roles of Eph receptors and ephrins in segmental patterning. Philos Trans R Soc Lond B Biol Sci 355:993-1002. CrossRef Medline

Yamamoto N, Tamada A, Murakami F (2002) Wiring of the brain by a range of guidance cues. Prog Neurobiol 68:393-407. CrossRef Medline

Yang T, Kersigo J, Jahan I, Pan N, Fritzsch B (2011) The molecular basis of making spiral ganglion neurons and connecting them to hair cells of the organ of Corti. Hear Res 278:21-33. CrossRef Medline

Ypsilanti AR, Zagar Y, Chédotal A (2010) Moving away from the midline: new developments for Slit and Robo. Development 137:1939-1952. CrossRef Medline

Yuan W, Zhou L, Chen JH, Wu JY, Rao Y, Ornitz DM (1999) The mouse SLIT family: secreted ligands for ROBO expressed in patterns that suggest 
a role in morphogenesis and axon guidance. Dev Biol 212:290-306. CrossRef Medline

Yuan W, Rao Y, Babiuk RP, Greer JJ, Wu JY, Ornitz DM (2003) A genetic model for a central (septum transversum) congenital diaphragmatic hernia in mice lacking Slit3. Proc Natl Acad Sci U S A 100:5217-5222. CrossRef Medline
Zine A, Aubert A, Qiu J, Therianos S, Guillemot F, Kageyama R, de Ribaupierre F (2001) Hes1 and Hes5 activities are required for the normal development of the hair cells in the mammalian inner ear. J Neurosci 21: 4712-4720. Medline 